\title{
Atmospheric trace gases support primary production in Antarctic desert surface soil
}

Mukan Ji ${ }^{1 *}$, Chris Greening ${ }^{2 *}$, Inka Vanwonterghem ${ }^{3}$, Carlo R. Carere ${ }^{4}$, Sean K. Bay ${ }^{2}$, Jason A. Steen ${ }^{3}$, Kate Montgomery ${ }^{1}$, Thomas Lines ${ }^{2}$, John Beardall ${ }^{2}$, Josie van Dorst ${ }^{1}$, Ian Snape ${ }^{5}$, Matthew B. Stott ${ }^{4}$, Philip Hugenholtz ${ }^{3}$ \& Belinda C. Ferrari ${ }^{1}$

Cultivation-independent surveys have shown that the desert soils of Antarctica harbour surprisingly rich microbial communities $^{1-3}$. Given that phototroph abundance varies across these Antarctic soils ${ }^{2,4}$, an enduring question is what supports life in those communities with low photosynthetic capacity ${ }^{3,5}$. Here we provide evidence that atmospheric trace gases are the primary energy sources of two Antarctic surface soil communities. We reconstructed $23 \mathrm{draft}$ genomes from metagenomic reads, including genomes from the candidate bacterial phyla WPS-2 and AD3. The dominant community members encoded and expressed high-affinity hydrogenases, carbon monoxide dehydrogenases, and a RuBisCO lineage known to support chemosynthetic carbon fixation $^{6,7}$. Soil microcosms aerobically scavenged atmospheric $\mathrm{H}_{2}$ and $\mathrm{CO}$ at rates sufficient to sustain their theoretical maintenance energy and mediated substantial levels of chemosynthetic but not photosynthetic $\mathrm{CO}_{2}$ fixation. We propose that atmospheric $\mathrm{H}_{2}, \mathrm{CO}_{2}$ and $\mathrm{CO}$ provide dependable sources of energy and carbon to support these communities, which suggests that atmospheric energy sources can provide an alternative basis for ecosystem function to solar or geological energy sources ${ }^{8,9}$. Although more extensive sampling is required to verify whether this process is widespread in terrestrial Antarctica and other oligotrophic habitats, our results provide new understanding of the minimal nutritional requirements for life and open the possibility that atmospheric gases support life on other planets.

Terrestrial Antarctica is among the most extreme environments on Earth. Its inhabitants experience the cumulative stresses of freezing temperatures, limited carbon, nitrogen and water availability, strong UV radiation, and frequent freeze-thaw cycles ${ }^{2,10,11}$. Although it was once believed that these conditions restrict life, we now know that the continent hosts a surprising diversity of macrofauna and microbiota ${ }^{1,2,12}$. Surveys indicate that the phylum-level composition of microbial communities in Antarctic soils is similar to those of temperate soils ${ }^{3}$, but Antarctic communities are highly specialized at the species level and strongly structured by physicochemical factors ${ }^{1,3,10}$. In many Antarctic soils, microorganisms are thought to live in dormant states ${ }^{2}$, with metabolic energy directed towards cell maintenance rather than growth ${ }^{13}$. However, it is unclear how these communities obtain the energy and carbon needed for maintenance, given that these soils are often low in organic carbon and contain few classical primary producers ${ }^{2,5}$. Cyanobacteria and algae are known primary producers in such ecosystems ${ }^{2,4}$, but multiple sites have now been described at which phototrophs are present in low abundance or restricted to lithic niches $5,11,14$. These findings suggest that unidentified energy and carbon sources may also support ecosystem function. Here, we used shotgun metagenomics and biochemical measurements to clarify the basis of primary production in two such Antarctic sites.
Three surface soils were initially sampled from Robinson Ridge (Wilkes Land) ${ }^{11}$ (Extended Data Fig. 1). Physicochemical analysis showed that the soils were low in total organic carbon $(0.13-0.24 \%)$, nitrogen $(0.012-0.023 \%)$, and moisture $(4.0-5.6 \%)$ content (Supplementary Table 1). We used shotgun DNA sequencing to produce a 264-MB metagenome from these soils, comprising 208,233 predicted genes (Supplementary Table 2) and 451 predicted $16 \mathrm{~S} / 18 \mathrm{~S}$ rRNA operational taxonomic units (OTUs) (Supplementary Table 3). The communities were dominated by Actinobacteria, Chloroflexi, Proteobacteria, Acidobacteria, and two candidate phyla, AD3 and WPS-2 (Fig. 1a). Identified phototrophs were limited to Cyanobacteria, with an average relative abundance of $0.28 \%$ (Fig. 1a). Consistent with other studies ${ }^{5,11,14}$, the low photosynthetic capacity and organic carbon content of Robinson Ridge soils contrasts with the inferred bacterial diversity, suggesting that alternative energy sources support these communities. To gain a deeper understanding of ecosystem function, we applied differential coverage binning ${ }^{15}$, which has been used to construct genomes of uncultured inhabitants of diverse environments ${ }^{15-18}$. We constructed $23 \mathrm{draft}$ genomes from the Robinson Ridge metagenome, including two WPS-2 and three AD3 genomes (Fig. 1b; Supplementary Table 4). These candidate phyla affiliate with the Terrabacteria superphylum ${ }^{16}$ and are sister lineages to Chloroflexi and Armatimonadetes ${ }^{19}$ (Extended Data Fig. 2).

We subsequently analysed the metabolic potential of the metagenome and derived genomes (Extended Data Fig. 3). All 23 sequenced organisms harboured terminal oxidase genes to sustain aerobic respiration, consistent with their aerated habitat, and genes for the oxidation of organic carbon compounds were also abundant (Supplementary Tables 5, 6). Genes supporting $\mathrm{CO}_{2}$ fixation through the Calvin-Benson-Bassham (CBB) cycle were unexpectedly widespread, being found in the genomes of Actinobacteria, WPS-2, and AD3 (Fig. 1b, Supplementary Table 5). Phylogenetic analysis revealed that these genomes encoded the type IE ribulose-1,5-bisphosphate carboxylase (RuBisCO) $(r b c L 1 E)^{6,7}$ (Fig. 2b, Extended Data Fig. 4a, b); this lineage is known to support hydrogenotrophic growth of Actinobacteria ${ }^{7}$, but is absent from phototrophs. In addition, enzymes responsible for the aerobic respiration of molecular $\mathrm{H}_{2}{ }^{20-22}$ and $\mathrm{CO}^{23,24}$ were encoded in multiple genomes (Fig. 1b, Supplementary Table 5). The high-affinity lineages identified-namely the structural genes encoding group $1 \mathrm{~h}[\mathrm{NiFe}]$-hydrogenases ( $h h y L$ and hhyS) (Fig. 2a, Extended Data Fig. 5a) and type I [MoCu]-carbon monoxide dehydrogenases ( $\operatorname{cox} L, \operatorname{coxS}$ and $\operatorname{cox} M$ ) (Extended Data Fig. 6a)-support scavenging of $\mathrm{H}_{2}$ and $\mathrm{CO}$ at the trace concentrations found in the atmosphere ${ }^{21,25}$. We also identified determinants of methanotrophy, ammonia oxidation, nitrogen cycling, and psychrotolerance (Supplementary Tables 5, 7-9).

Collectively, the metagenome data suggest that Antarctic surface soil microbial communities have the capacity to scavenge $\mathrm{H}_{2}, \mathrm{CO}_{2}$ and

\footnotetext{
${ }^{1}$ School of Biotechnology and Biomolecular Sciences, Australian Centre for Astrobiology, UNSW Sydney, Randwick, New South Wales 2052 , Australia. ${ }^{2}$ School of Biological Sciences, Centre for Geometric Biology, Monash University, Clayton, Victoria 3800, Australia. ${ }^{3}$ Australian Centre for Ecogenomics, School of Chemistry and Molecular Biosciences, The University of Queensland, St. Lucia, Queensland 4072, Australia. ${ }^{4}$ GNS Science, Wairakei Research Centre, 114 Karetoto Road, Wairakei, Taupō 3384, New Zealand. ${ }^{5}$ Australian Antarctic Division, Department of Sustainability, Environment, Water, Population and Communities. 203 Channel Highway, Kingston, Tasmania 7050, Australia.

*These authors contributed equally to this work.
} 


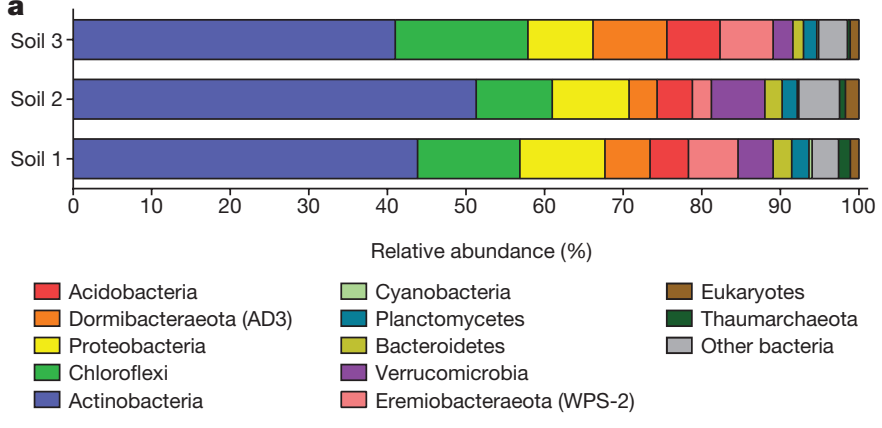

b

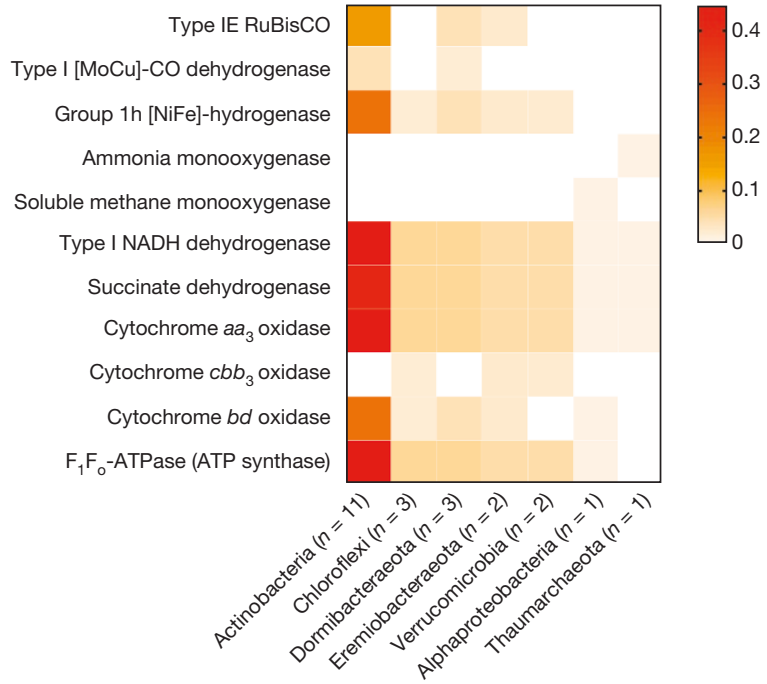

Figure 1 | Phylogenetic and functional composition of Robinson Ridge soils. a, Microbial community structure of three biologically independent soil samples, as determined by mapping sequence reads onto a database of bacterial, archaeal and eukaryotic $16 \mathrm{~S} / 18 \mathrm{~S}$ rRNA genes. b, Heat map showing the relative abundance of genes encoding key enzymes involved in carbon fixation and energy conservation. The relative abundance was calculated on the basis of the presence or absence of functional genes within the sequenced genomes from three biologically independent soil samples, and is presented relative to the total number of $16 \mathrm{~S}$ rRNA gene sequences in the total microbial community.

CO from the atmosphere for use as energy and carbon sources. We confirmed this theory by detecting both the expression and activity of the enzymes catalysing these processes in Robinson Ridge soils. Reverse transcription (RT)-PCR confirmed the expression of the genes encoding type IE RuBisCO $(r b c L 1 E)$, high-affinity hydrogenase $(h h y L)$, and carbon monoxide dehydrogenases ( $\operatorname{cox} L)$ (Extended Data Fig. 7). Gas chromatography experiments showed that the soil communities aerobically oxidized atmospheric $\mathrm{H}_{2}$ and $\mathrm{CO}$ (threshold of 190 parts per billion by volume (p.p.b.v.) $\mathrm{H}_{2}$ and 20 p.p.b.v. CO; rate of $3.49 \mathrm{nmol}$ atmospheric $\mathrm{H}_{2}$ per hour per gram dry weight and $0.42 \mathrm{nmol}$ atmospheric CO per hour per gram dry weight) (Fig. 3a; Extended Data Fig. 6b; Supplementary Table 10 ), with $\mathrm{H}_{2}$ oxidation also measurable at $-12^{\circ} \mathrm{C}$ (Extended Data Fig. 5b). However, we did not observe atmospheric methane oxidation, despite recovering the genome of a putative alphaproteobacterial methanotroph. We next measured the capacity of the soils to fix carbon by tracing assimilation of ${ }^{14} \mathrm{C}$-labelled $\mathrm{CO}_{2}$. Although basal levels of $\mathrm{CO}_{2}$ fixation were variable (Extended Data Fig. 4c, d), the addition of $\mathrm{H}_{2}$ stimulated $\mathrm{CO}_{2}$ fixation by an average of twofold (Fig. 3b). By contrast, light stimulation had no consistent effect (Fig. 3b).

To ensure that the use of $\mathrm{H}_{2}, \mathrm{CO}_{2}$ and $\mathrm{CO}$ from the atmosphere as energy and carbon sources was not an isolated phenomenon, we sampled another Antarctic site: Adams Flat (Princess Elizabeth Land) (Extended Data Fig. 1). We collected three soils (Supplementary Table 1) a

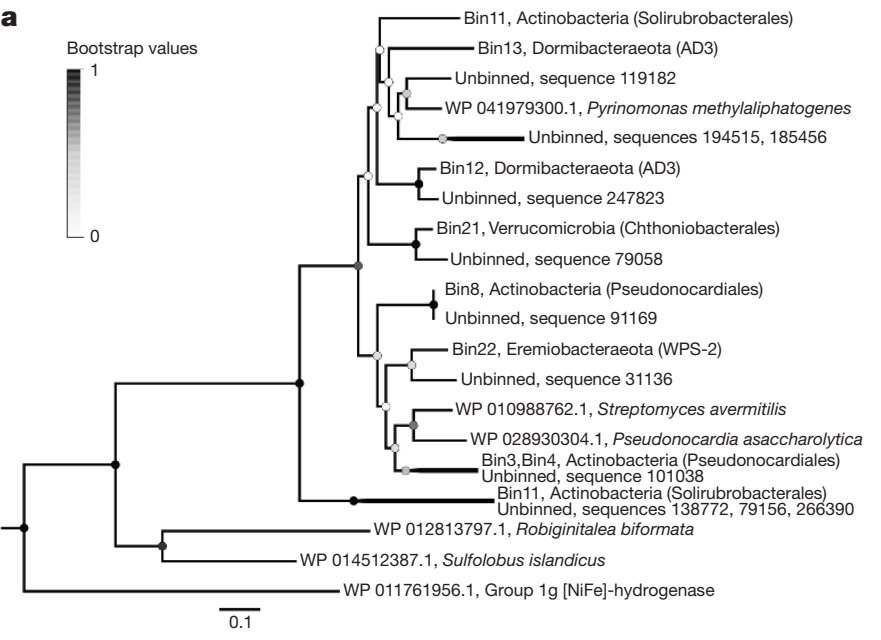

b

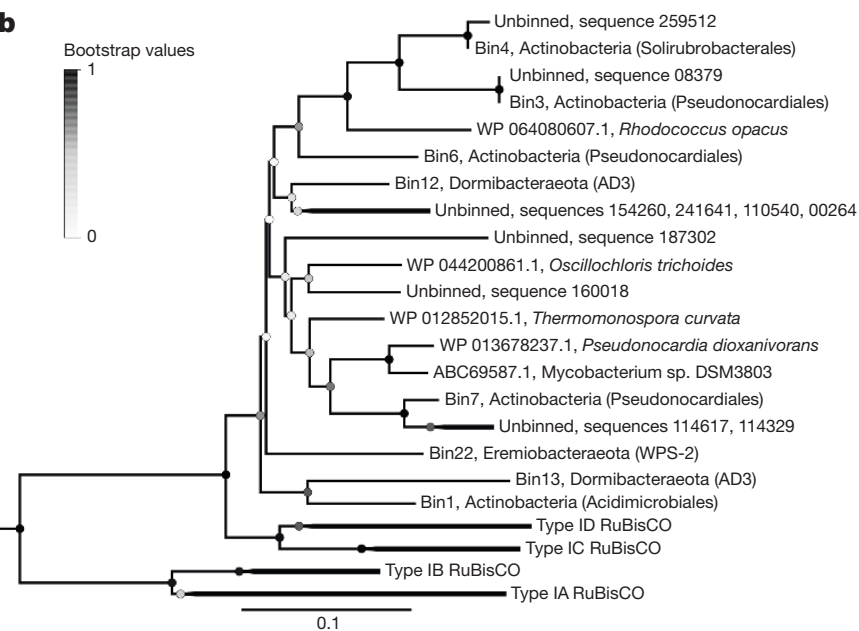

Figure 2 Determinants of trace gas oxidation and chemotrophic carbon fixation in Robinson Ridge soils. Maximum-likelihood phylogenetic trees of the enzyme families responsible for atmospheric $\mathrm{H}_{2}$ respiration (a, $h h y L$; group $1 \mathrm{~h}[\mathrm{NiFe}]$ hydrogenase) and chemosynthetic $\mathrm{CO}_{2}$ fixation (b, rbcL1E; type IE RuBisCO). Protein sequences retrieved from the metagenome and reconstructed genomes were aligned against reference sequences (bootstrapped with 500 replicates).

with low organic carbon content and high Actinobacteria-low Cyanobacteria communities (Extended Data Fig. 8). Enzymes responsible for trace gas scavenging were expressed and active in these soils (Fig. 3a; Extended Data Figs 6b, 7; Supplementary Table 10), and $\mathrm{H}_{2}$ supplementation stimulated carbon fixation by an average of eightfold $(P=0.0039)$ (Fig. 3b). In further support of the theory that trace gas scavenging operates in a range of Antarctic desert sites, analysis of public metagenomes revealed that $h h y L, \operatorname{cox} L$, and $r b c L 1 E$ genes are relatively abundant in the McMurdo Dry Valleys region (Extended Data Fig. 9).

On the basis of these findings, we propose that the two Antarctic sites sampled harbour largely dormant microbial communities that conserve energy by oxidation of atmospheric trace gases (Fig. 4). Biochemical studies showed that soils oxidize atmospheric $\mathrm{H}_{2}$ and $\mathrm{CO}$ at rates that are theoretically sufficient to sustain the energy needs of their microbial communities; assuming $1.4 \times 10^{14}$ cells per $\mathrm{C}$-mol of biomass (the amount of biomass that contains 1 mol carbon) and a maintenance energy of $1.68 \mathrm{~kJ}$ per $\mathrm{C}$-mol biomass per hour at $10^{\circ} \mathrm{C}^{22,26}$, the rates of atmospheric $\mathrm{H}_{2}$ and $\mathrm{CO}$ oxidation observed can support $5.5 \times 10^{7}$ bacteria per gram of Robinson Ridge soil and $8.0 \times 10^{7}$ bacteria per gram of Adams Flat soil (Supplementary Table 10). Consistently, pure culture studies have shown that trace gas scavenging supports the persistence of diverse heterotrophic aerobes during organic carbon starvation $^{20,22,25}$. Atmospheric $\mathrm{H}_{2}$ and $\mathrm{CO}$ are dependable energy sources 

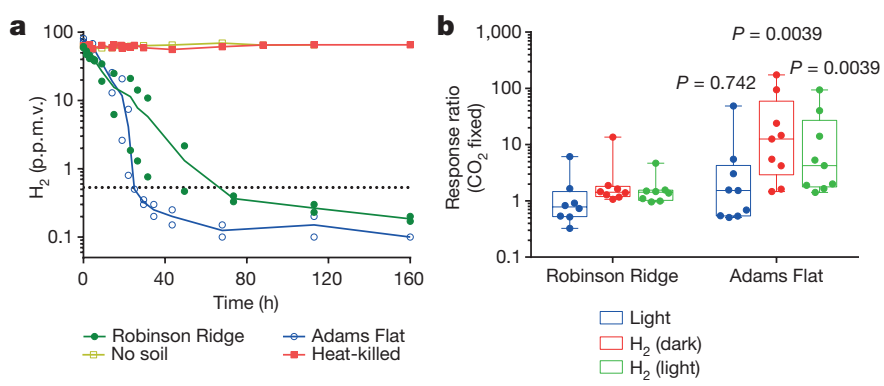

Figure 3 Trace gas oxidation and chemosynthetic carbon fixation in Antarctic desert soils. a, Gas chromatography measurements of oxidation of atmospheric $\mathrm{H}_{2}$ (mixing ratio, 0.53 parts per million by volume (p.p.m.v.)) at $10^{\circ} \mathrm{C}$. Values shown for two biologically independent soil samples (mean of technical triplicates). $\mathbf{b}$, Ratios of ${ }^{14} \mathrm{C}$-labelled $\mathrm{CO}_{2}$ assimilation following stimulation with light and/or $\mathrm{H}_{2}$. Results shown for two biologically independent Robinson Ridge soils (technical quadruplicate) and three biologically independent Adams Flat soils (technical triplicate). Centre values show medians; boxes show upper and lower quartiles; whiskers show maximum and minimum values. Where sample size was appropriate, statistical significance between paired technical replicates was tested using a two-tailed Wilcoxon signed-rank test.

for dormant bacteria as they are strong reductants, diffuse through cell membranes, and occur at low concentrations throughout the troposphere ${ }^{24,27,28}$.

Moreover, we propose that the primary producers in these communities are bacteria from the phyla Actinobacteria, AD3, and WPS-2 that generate biomass by consuming atmospheric $\mathrm{H}_{2}, \mathrm{CO}_{2}$ and $\mathrm{CO}$. Of the draft genomes harbouring group $1 \mathrm{~h}[\mathrm{NiFe}]$-hydrogenase genes, $55 \%$ also contained type IE RuBisCO genes (Fig. 2a, b; Supplementary Table 5), suggesting that some bacteria generate biomass through $\mathrm{H}_{2}$-driven $\mathrm{CO}_{2}$ fixation and others exclusively scavenge $\mathrm{H}_{2}$ for energy acquisition. The metagenomes suggest that minor community members may also assimilate carbon through the serine pathway (methanotrophs), the 3-hydroxypropionate pathway (ammonia oxidizers), and oxygenic photosynthesis (cyanobacteria). On the basis of the high completeness, minimal contamination, and monophyly of their genomes (Supplementary Table 4), we propose the names Candidatus Eremiobacteraeota (desert bacterial phylum) and Candidatus
Dormibacteraeota (dormant bacterial phylum) for candidate phyla WPS-2 and AD3, respectively (Supplementary Information). The type genera Candidatus Eremiobacter and Candidatus Dormibacter are also proposed, based on two of the obtained genome sequences (Ga011786,

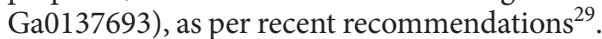

Overall, the microbial community structure of the two Antarctic sites sampled appears to be shaped by selection for bacteria that can persist in these physically extreme, chemically deprived environments. Microbial phototrophs are in low abundance, probably restricted by climatic conditions such as low water and nutrient availability, summer radiation, and winter darkness ${ }^{1}$. Instead, most inhabitants are inferred to be dormant heterotrophic aerobic bacteria that support energy generation and, in some cases, carbon fixation by oxidizing atmospheric trace gases. In oligotrophic Antarctic soils, there is evidence that aeolian processes drive some ecosystem recruitment from less hostile microenvironments (for example, hypolithons) and niche processes subsequently select for the most functionally specialized microorganism ${ }^{30}$; hence, the ability to scavenge trace gases is likely to be an important survival-determining trait that may influence ecosystem succession. Given the concurrent findings from Robinson Ridge, Adams Flat, and the public McMurdo Dry Valley metagenomes, trace gas scavenging may be a general mechanism in Antarctic desert soils. However, broader surveys are now needed to determine the distribution, significance, and role of this process in primary production and ecosystem succession in terrestrial Antarctica, particularly in comparison to phototrophy. Indeed, there are diverse Antarctic sites where phototrophs are dominant, including hypolithons and high-latitude or moist soils ${ }^{2,4}$. It is likely that both phototrophy and gas scavenging co-occur in many Antarctic sites, with the balance of these processes shifting depending on physicochemical factors. It will also be of interest to determine whether trace gas scavenging supports primary production in other oligotrophic ecosystems, for example the hyperarid deserts of Atacama, where Actinobacteria harbouring genes for trace gas scavenging are also dominant ${ }^{17}$. Whereas most ecosystems are driven by solar or geologically derived energy, primary production in these Antarctic desert surface soils appears to be supported by atmospheric trace gases.

Online Content Methods, along with any additional Extended Data display items and Source Data, are available in the online version of the paper; references unique to these sections appear only in the online paper.

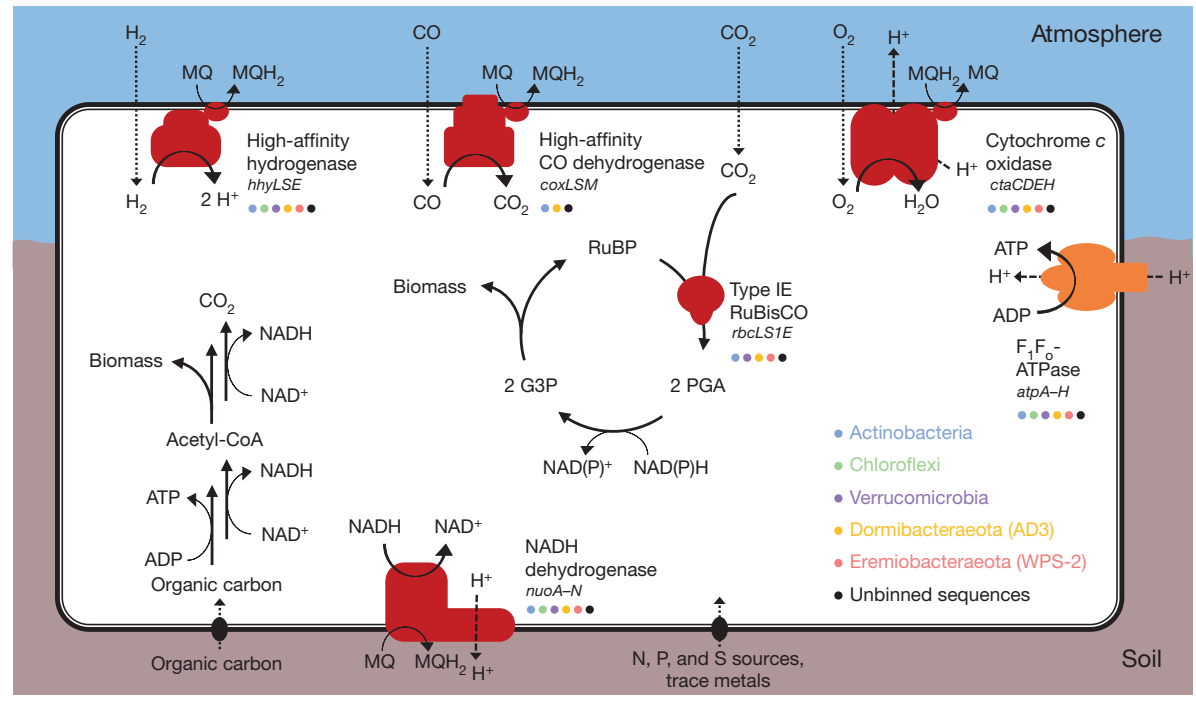

Figure 4 | Proposed metabolic capacity of the Robinson Ridge soil. Depicted are members of the five microbial phyla that are predicted to persist by trace gas scavenging. These phyla are variably capable of aerobic respiration of atmospheric $\mathrm{H}_{2}$ (all phyla) or $\mathrm{CO}$ (Actinobacteria, Dormibacteraeota), and chemosynthetic fixation of atmospheric $\mathrm{CO}_{2}$ (Actinobacteria, Dormibacteraeota, Eremiobacteraeota). It remains to be determined whether atmospheric $\mathrm{H}_{2}$ oxidation supports $\mathrm{NAD}(\mathrm{P})^{+}$ reduction through direct coupling or reverse electron transport, although direct coupling remains thermodynamically favourable at $10^{\circ} \mathrm{C}$ (Gibbs free energy of reaction $(\Delta G)=-19 \mathrm{~kJ} \mathrm{~mol}^{-1}$ ). The community is also predicted to respire the small amount of soil organic carbon present as it becomes bioavailable. 
Received 21 September 2016; accepted 9 November 2017.

Published online 6 December 2017.

1. Siciliano, S. D. et al. Soil fertility is associated with fungal and bacterial richness, whereas $\mathrm{pH}$ is associated with community composition in polar soi microbial communities. Soil Biol. Biochem. 78, 10-20 (2014).

2. Cary, S. C., McDonald, I. R., Barrett, J. E. \& Cowan, D. A. On the rocks: the microbiology of Antarctic Dry Valley soils. Nat. Rev. Microbiol. 8, 129-138 (2010).

3. Lee, C. K., Barbier, B. A., Bottos, E. M., McDonald, I. R. \& Cary, S. C. The Inter-Valley Soil Comparative Survey: the ecology of Dry Valley edaphic microbial communities. ISME J. 6, 1046-1057 (2012).

4. Chan, Y., Van Nostrand, J. D., Zhou, J., Pointing, S. B. \& Farrell, R. L. Functional ecology of an Antarctic Dry Valley. Proc. Natl Acad. Sci. USA 110, 8990-8995 (2013).

5. Ji, M. et al. Microbial diversity at Mitchell Peninsula, Eastern Antarctica: a potential biodiversity "hotspot". Polar Biol. 39, 237-249 (2015).

6. Tebo, B. M. et al. Microbial communities in dark oligotrophic volcanic ice cave ecosystems of Mt. Erebus, Antarctica. Front. Microbiol. 6, 179 (2015).

7. Grostern, A. \& Alvarez-Cohen, L. RubisCO-based $\mathrm{CO} 2$ fixation and $\mathrm{C} 1$ metabolism in the actinobacterium Pseudonocardia dioxanivorans CB1190. Environ. Microbiol. 15, 3040-3053 (2013).

8. Kelley, D. S. et al. A serpentinite-hosted ecosystem: the Lost City hydrothermal field. Science 307, 1428-1434 (2005).

9. Cavicchioli, R. Microbial ecology of Antarctic aquatic systems. Nat. Rev. Microbiol. 13, 691-706 (2015).

10. Pointing, S. B. et al. Highly specialized microbial diversity in hyper-arid polar desert. Proc. Natl Acad. Sci. USA 106, 19964-19969 (2009).

11. Ferrari, B. C. et al. Geological connectivity drives microbial community structure and connectivity in polar, terrestrial ecosystems. Environ. Microbiol. 18, 1834-1849 (2016)

12. Chown, S. L. et al. The changing form of Antarctic biodiversity. Nature $\mathbf{5 2 2}$ 431-438 (2015).

13. Lennon, J. T. \& Jones, S. E. Microbial seed banks: the ecological and evolutionary implications of dormancy. Nat. Rev. Microbiol. 9, 119-130 (2011).

14. Chanal, A. et al. The desert of Tataouine: an extreme environment that hosts a wide diversity of microorganisms and radiotolerant bacteria. Environ. Microbiol. 8, 514-525 (2006).

15. Albertsen, M. et al. Genome sequences of rare, uncultured bacteria obtained by differential coverage binning of multiple metagenomes. Nat. Biotechnol. 31 , 533-538 (2013).

16. Rinke, C. et al. Insights into the phylogeny and coding potential of microbial dark matter. Nature 499, 431-437 (2013)

17. Lynch, R. C., Darcy, J. L., Kane, N. C., Nemergut, D. R. \& Schmidt, S. K. Metagenomic evidence for metabolism of trace atmospheric gases by high-elevation desert Actinobacteria. Front. Microbiol. 5, 698 (2014).

18. Howe, A. C. et al. Tackling soil diversity with the assembly of large, complex metagenomes. Proc. Natl Acad. Sci. USA 111, 4904-4909 (2014).

19. Lee, K. C. et al. Phylogenetic delineation of the novel phylum Armatimonadetes (former candidate division OP10) and definition of two novel candidate divisions. Appl. Environ. Microbiol. 79, 2484-2487 (2013).

20. Greening, C. et al. Persistence of the dominant soil phylum Acidobacteria by trace gas scavenging. Proc. Natl Acad. Sci. USA 112, 10497-10502 (2015).

21. Greening, C. et al. Genomic and metagenomic surveys of hydrogenase distribution indicate $\mathrm{H}_{2}$ is a widely utilised energy source for microbial growth and survival. ISME J. 10, 761-777 (2016).

22. Constant, P., Chowdhury, S. P., Pratscher, J. \& Conrad, R. Streptomycetes contributing to atmospheric molecular hydrogen soil uptake are widespread and encode a putative high-affinity [NiFe]-hydrogenase. Environ. Microbiol. 12, 821-829 (2010)

23. Quiza, L., Lalonde, I., Guertin, C. \& Constant, P. Land-use influences the distribution and activity of high affinity $\mathrm{CO}$-oxidizing bacteria associated to type I-coxL genotype in soil. Front. Microbiol. 5, 271 (2014).
24. King, G. M. \& Weber, C. F. Distribution, diversity and ecology of aerobic CO-oxidizing bacteria. Nat. Rev. Microbiol. 5, 107-118 (2007).

25. Berney, M., Greening, C., Hards, K., Collins, D. \& Cook, G. M. Three different [NiFe] hydrogenases confer metabolic flexibility in the obligate aerobe Mycobacterium smegmatis. Environ. Microbiol. 16, 318-330 (2014).

26. Conrad, R. Soil microorganisms oxidizing atmospheric trace gases $\left(\mathrm{CH}_{4}, \mathrm{CO}\right.$, $\mathrm{H}_{2}$, NO). Indian J. Microbiol. 39, 193-203 (1999).

27. Baani, M. \& Liesack, W. Two isozymes of particulate methane monooxygenase with different methane oxidation kinetics are found in Methylocystis sp. strain SC2. Proc. Natl Acad. Sci. USA 105, 10203-10208 (2008)

28. Greening, C. et al. Atmospheric hydrogen scavenging: from enzymes to ecosystems. Appl. Environ. Microbiol. 81, 1190-1199 (2015).

29. Whitman, W. B. Modest proposals to expand the type material for naming of prokaryotes. Int. J. Syst. Evol. Microbiol. 66, 2108-2112 (2011).

30. Herbold, C. W., Lee, C. K., McDonald, I. R. \& Cary, S. C. Evidence of global-scale aeolian dispersal and endemism in isolated geothermal microbial communities of Antarctica. Nat. Commun. 5, 3875 (2014).

Supplementary Information is available in the online version of the paper.

Acknowledgements We thank the Australian Antarctic Division expedition teams who obtained Antarctic soils and photos used in this study. We also thank S. Siciliano for soil sampling, D. Wilkins for the map, T. Mooney for the Adams Flat photo, M. Chuvochina and A. Oren for etymological advice, and S. Chown for valuable insights. This work was supported by Bioplatforms Australia, an Australian Antarctic Science project grant (4406; awarded to B.C.F., C.G., M.B.S. and I.S.), an ARC Future Fellowship (FT170100341; awarded to B.C.F.), an ARC DECRA Fellowship (DE170100310; awarded to C.G.), an ARC DORA and Laureate Fellowship (DP120103498 and FL150100038; awarded to P.H.), and a Marsden Grant (16-GNS-035; awarded to C.R.C. and C.G.). UNSW Sydney, the Centre for Geometric Biology (Monash University), and the Geothermal Resources of New Zealand research program (GNS Science) also provided funding to support this research.

Author Contributions B.C.F. determined the research objective with input from all authors. I.S. provided access to soils and site information. P.H., I.V. and J.A.S. conducted metagenome sequencing and binning. M.J., B.C.F., C.G., I.V., J.v.D., J.A.S. and M.B.S. performed metagenome and genome analysis. C.G., M.J., I.V. and J.A.S. conducted phylogenetic tree inferences. M.J., J.v.D. and B.C.F. carried out RT-PCR. C.R.C., M.B.S., C.G. and K.M. carried out GC analysis. C.G., S.K.B., J.B. and T.L. conducted carbon fixation analysis. M.J., B.C.F., C.G., C.R.C., I.V., M.B.S., P.H. and S.K.B. conducted data analysis. B.C.F., C.G. and M.J. wrote the manuscript with input from all remaining authors; all authors have read and approved the manuscript for submission.

Author Information Reprints and permissions information is available at www.nature.com/reprints. The authors declare no competing financial interests. Readers are welcome to comment on the online version of the paper. Publisher's note: Springer Nature remains neutral with regard to jurisdictional claims in published maps and institutional affiliations. Correspondence and requests for materials should be addressed to B.C.F. (b.ferrari@unsw.edu.au).

Reviewer Information Nature thanks D. Cowan, N. Fierer, J. Schimel and the other anonymous reviewer(s) for their contribution to the peer review of this work.

This work is licensed under a Creative Commons Attribution 4.0 International (CC BY 4.0) licence. The images or other third party material in this article are included in the article's Creative Commons licence, unless indicated otherwise in the credit line; if the material is not included under the Creative Commons licence, users will need to obtain permission from the licence holder to reproduce the material. To view a copy of this licence, visit http://creativecommons.org/licenses/by/4.0/. 


\section{METHODS}

No statistical methods were used to predetermine sample size. The experiments were not randomized and the investigators were not blinded to allocation during experiments and outcome assessment.

Site description and sample collection. This study focused on two coastal ice-free sites in different regions of eastern Antarctica. Robinson Ridge $(-66.367739,110.585262)$, located $10 \mathrm{~km}$ south of Casey station in the Windmill Islands coast of Wilkes Land (Extended Data Fig. 1a, b), is part of a pristine polar desert (Extended Data Fig. 1c). Adams Flat $(-68.5502,78.02106)$ is located $242 \mathrm{~km}$ from Davis station in the Vestfold Hills regions of Princess Elizabeth Land (Extended Data Fig. 1d). Both sites are devoid of vascular plants, but harbour a limited diversity of macrofauna, with tardigrades and nematodes shown to be present in Robinson Ridge ${ }^{31}$. Three surface soil samples ( $100 \mathrm{~g}$ ) from the top $10 \mathrm{~cm}$ of the soil profile were collected in December 2005 for a previous study on Robinson Ridge ${ }^{1}$ and January 2014 for Adams Flat. For both sites, samples were collected along a spatially explicit sampling design comprised of three 300-m-long transects ${ }^{1,11,32}$ separated by 2 -m distances from each other. As these soils were included in the Australian Antarctic Divisions polar soil archive, samples were sieved down to $63 \mu \mathrm{m}$, aliquoted into $5-25$-g subsamples, and stored at $-80^{\circ} \mathrm{C}$ until analysis.

Physicochemical analysis. Latitude, longitude, slope, aspect and elevation were recorded for each sample taken using ARC GIS software (ESRI). For all soils, detailed physical and chemical data were analysed in-house using standard procedures. Total carbon, nitrogen, and phosphorus, $\mathrm{pH}$, water-holding capacity, grain size, and conductivity were recorded ${ }^{1}$. In addition, extractable ions were measured $\left(\mathrm{Cl}^{-}, \mathrm{Br}^{-}, \mathrm{NO}_{3}{ }^{-}, \mathrm{NO}_{2}{ }^{-}, \mathrm{PO}_{4}{ }^{3-}, \mathrm{SO}_{4}{ }^{2-}\right.$ and $\left.\mathrm{NH}_{4}{ }^{+}\right)$and $\mathrm{X}$-ray fluorescence elemental analysis was conducted $\left(\mathrm{SiO}_{2}, \mathrm{TiO}_{2}, \mathrm{Al}_{2} \mathrm{O}_{3}, \mathrm{Fe}_{2} \mathrm{O}_{3}, \mathrm{MnO}, \mathrm{MgO}, \mathrm{CaO}\right.$, $\mathrm{Na}_{2} \mathrm{O}, \mathrm{K}_{2} \mathrm{O}, \mathrm{P}_{2} \mathrm{O}_{5}, \mathrm{SO}_{3}$ and $\mathrm{Cl}$ ). The soils were low in total organic carbon content (average $0.17 \%$ for Robinson Ridge, $0.09 \%$ for Adams Flat) and moisture measured as dry matter fraction (average $4.4 \%$ for Robinson Ridge, $0.42 \%$ for Adams Flat) (Supplementary Table 1).

Community DNA extraction. Total community DNA was extracted from the six soil samples for microbial community profiling and functional metagenomic analysis. In all cases, DNA was extracted from $0.25-0.3 \mathrm{~g}$ of each sample in technical triplicate using the FastDNA SPIN Kit for Soil (MP Biomedicals). All DNA extracts were quantified and DNA lysate quality was evaluated using automated ribosomal intergenic spacer analysis (ARISA) as described ${ }^{32}$.

Metagenome sequencing, assembly, and binning. For the three Robinson Ridge samples, DNA was extracted in triplicate and used for shotgun metagenome sequencing. Metagenome libraries were prepared using the Nextera DNA Library Preparation Kit (Illumina) and sequenced using three-fifths of an Illumina HiSeq2000 flowcell lane at the Institute for Molecular Biosciences (University of Queensland). The raw reads $(2 \times 100$-bp reads, $14.9 \mathrm{~Gb})$ were processed using Trimmomatic ${ }^{33}$ for adaptor removal and quality filtering, and BBMap to merge overlapping reads. The processed reads were combined into a large co-assembly using the de novo assembly algorithm in CLC Genomics Workbench v8 (CLC Bio) and gaps within scaffolds were closed using abyss-sealer ${ }^{34}$. Processed reads from each dataset were mapped onto the co-assembly with BamM. The scaffolds were binned on the basis of differential coverage profiles, $k$-mer frequencies, and GC content using Groop $\mathrm{M}^{35}$ and MetaBAT ${ }^{36}$. Population genome bins obtained with GroopM were further refined using the GroopM refine function. The genome completeness and contamination were estimated with $\mathrm{CheckM}^{37}$ by calculating the presence of lineage-specific single-copy marker genes. The two sets of population genomes from the GroopM and MetaBAT binning were compared using RefineM to identify possible duplicates. Twenty-three genomes ( $>50 \%$ completeness, $<10 \%$ contamination) were selected for further analysis and accounted for $56-65 \%$ of total reads obtained from the three soil samples. Of these, 11 genomes were estimated to be more than $90 \%$ complete and less than 5\% contaminated (Supplementary Table 4).

Community analysis. We determined the microbial community structure of the three soil samples from Robinson Ridge and three from Adams Flat. For both sites, the bacterial and archaeal community structure was determined by $16 \mathrm{~S}$ rRNA gene amplicon sequencing as described previously $y^{32,38}$. Community alpha diversity was inferred from the amplicon sequencing data by calculating observed richness, Chaol, and the Shannon index $\left(\mathrm{H}^{\prime}\right)$ as described ${ }^{11}$. For the Robinson Ridge samples only, bacterial, archaeal, and eukaryote community structure was also determined by retrieving $16 \mathrm{~S}$ and $18 \mathrm{~S}$ rRNA genes from the metagenomes. Community composition profiles were generated with CommunityM by mapping reads onto a database of bacterial, archaeal and eukaryotic $16 \mathrm{~S}$ and $18 \mathrm{~S}$ rRNA genes (that is, the SILVA $^{39}$ and GreenGenes ${ }^{40}$ databases clustered at $97 \%$ similarity). To infer the phylogeny of WPS-2 and AD3, a genome tree was generated using 38 universal conserved marker genes ${ }^{41}$ from 4,624 bacterial and archaeal genomes retrieved from the Integrated Microbial Genomes database (IMG) ${ }^{42}$ together with the recovered population genomes. A concatenated alignment of the marker genes was used to generate the genome tree with FastTree ${ }^{43}$ and the tree was visualized in $\mathrm{iTOL}^{44}$. Functional analysis. The population genomes derived from Robinson Ridge were functionally annotated using Prokka ${ }^{45}$ and the KEGG Orthology database (Kyoto Encyclopedia of Genes and Genomes ${ }^{46}$. Genes specifically involved in carbohydrate metabolism were identified using dbCAN, an HMM-based database for carbohydrate-active enzyme (CAZy $)^{47}$ annotation. Potential secondary metabolite biosynthesis gene clusters were identified using antiSMASH ${ }^{48}$. [NiFe]-hydrogenase, $[\mathrm{MoCu}]$-carbon monoxide dehydrogenase, and RuBisCO enzymes encoded within the metagenome were classified by constructing phylogenetic trees of their catalytic subunits ${ }^{21,49,50}$. The derived protein sequences encoding the catalytic subunits of these enzymes were aligned with reference sequences reported in previous studies $^{21,49,50}$ using ClustalX ${ }^{51}$. Evolutionary relationships were visualized on phylogenetic trees constructed with MEGA $7^{52}$ using the maximum-likelihood method. Trees were bootstrapped using 500 replicates and rooted with suitable outgroup sequences. The relative abundance of $h h y L$, coxL, and $r b c L 1 E$ in McMurdo Dry Valley samples was determined by retrieving ten public metagenomes through the Joint Genome Institute (JGI IDs 104803, 106649, 35851, 3300002548, 3300012042, $3300012045,3300012185,3300012188,3300012527$, and 3300012678). The genes of interest were retrieved from the downloaded metagenomes by BLAST using the $h h y L, \operatorname{cox} L$, and $r b c L 1 E$ gene sequences identified from the Robinson Ridge metagenome as queries. The identity of the retrieved type I cox $L$ and type IE $r b c L$ large subunit genes was confirmed by constructing phylogenetic trees as described above, whereas genes encoding group $1 \mathrm{~h}[\mathrm{NiFe}]$-hydrogenase large subunits were identified using $\mathrm{HydDB}^{53}$. The relative abundance of the three genes was compared with those in five public forest metagenomes (JGI IDs 66726, 69782, 92543 , 94443, 109646)

RT-PCR analysis. We used RT-PCR to confirm the expression of the genes of interest by the microbial communities within the six soil samples. RNA was extracted from $2 \mathrm{~g}$ from each of the six soil samples using the MoBio PowerSoil Total RNA Isolation kit (MO BIO). All RNA extracts were quantified using the RNA Analysis Kit (Agilent) and cDNA was synthesized using Maxima First Strand cDNA Synthesis Kit (Thermo Fisher Scientific). RT-PCR was used to confirm the expression of the group $1 \mathrm{~h}$ [NiFe]-hydrogenase large subunit gene $h$ hyL (primers NiFe-244f: 5'-GGGATCTGCGGGGACAACCA-3'; NiFe568r: 5'-TCTCCCGGGTGTAGCGGCTC-3') and the type I [MoCu]-carbon monoxide dehydrogenase large subunit gene coxL (primers type1-1288f 5'-TSKKYACSGGCWSSTA-3'; type1-1540r: 5'-TAYGAYWSSGGYRAYTA-3') using previously described degenerate primers, mixtures, and thermal cycler conditions $^{23,54}$. Expression of the type IE RuBisCO large subunit gene ( $\left.r b c L 1 E\right)$ was confirmed using specifically designed primers based on the sequences obtained from Robinson Ridge (rbcL1Ef: 5'-GGACBGTSGTVTGGACSGA-3'; rbcL1Er $5^{\prime}$-TTGAABCCRAAVACRTTGCC- $3^{\prime}$ ). For this gene, the RT-PCR mixtures were comprised of $1 \times$ Promega reaction buffer (Promega), $0.4 \mathrm{mM}$ deoxynucleotide triphosphates, $0.4 \mathrm{nM}$ of each primer, $0.1 \mathrm{mg} \mathrm{ml}^{-1}$ bovine serum albumin, $1.25 \mathrm{U}$ Go-Taq polymerase (Promega), $1 \mu \mathrm{l}$ diluted $\mathrm{cDNA}$, and nuclease-free water to a final volume of $25 \mu \mathrm{l}$. A standard PCR protocol was used for the type IE RuBisCO large subunit gene as follows: $95^{\circ} \mathrm{C}$ for $5 \mathrm{~min} ; 30$ cycles of denaturing at $95^{\circ} \mathrm{C}$ for $30 \mathrm{~s}$, annealing at $55^{\circ} \mathrm{C}$ for $30 \mathrm{~s}$ and extension at $72^{\circ} \mathrm{C}$ for $30 \mathrm{~s}$; and a final extension of $72^{\circ} \mathrm{C}$ for $5 \mathrm{~min}$. Owing to the high degeneracy of coxL PCR primers, multiple bands were produced after thermal cycling. To confirm the identity of the PCR products, bands were separated by gel electrophoresis, the band of the correct size (780 bp) was excised aseptically, and its DNA was extracted using the Zymoclean Gel DNA Recovery Kit (Zymol). For hydrogenase and RuBisCO, purified PCR products were cloned and transformed using the pGEM-T Easy Vector System (Promega). The purified coxL PCR products and positive hydrogenase and $\mathrm{RuBisCO}$ clones were sequenced using Sanger sequencing at the Ramaciotti Center for Gene Function Analysis (Sydney). The identity of all sequenced clones was confirmed using NCBI BLAST against the nucleotide database.

Gas chromatography analysis. We used gas chromatography to determine whether the microbial communities in the collected soil samples scavenged atmospheric $\mathrm{H}_{2}, \mathrm{CO}$, or $\mathrm{CH}_{4}$. Soil samples of $1 \mathrm{~g}$ were placed into sterile $114-\mathrm{ml}$ serum bottles and sealed with butyl rubber stoppers. $\mathrm{H}_{2}, \mathrm{CO}$, or $\mathrm{CH}_{4}$ gas was then added to achieve final initial headspace concentrations of $\sim 60$ p.p.m.v., $\sim 5$ p.p.m.v., or $\sim 50$ p.p.m.v., respectively. Soil incubation temperatures were monitored throughout using a 51II single input digital thermometer (Fluke). Headspaces ( $1 \mathrm{ml}$ ) were sampled in situ using a gas-tight syringe (VICI Precision Sampling). $\mathrm{H}_{2}$ and CO partial pressures were measured using a PP1 Gas Analyser (Peak Performer) equipped with a reducing compound photometer (RCP: $\mathrm{H}_{2}, \mathrm{CO}$ ), flame ionizing detector (FID: $\mathrm{CH}_{4}$ ), Unibeads $1 \mathrm{~S}$ 60/80 column, and Molecular Sieve 13X 60/80 column, as previously described ${ }^{20}$. Samples were calibrated against $\mathrm{H}_{2}, \mathrm{CO}$, and $\mathrm{CH}_{4}$ standards 
prepared in advance. The experiments each used two biologically independent Robinson Ridge and two biologically independent Adams Flat soil samples. Gas chromatography traces were recorded of technical triplicates for all $\mathrm{H}_{2}$ measurements and technical duplicates for all CO measurements. Two negative controls, namely heat-killed soils $\left(1 \mathrm{~g} ; 121^{\circ} \mathrm{C}, 15\right.$ p.s.i., $\left.20 \mathrm{~min}\right)$ and serum bottles without soil, were monitored in parallel to regular sampling to ensure that the observed reduction of $\mathrm{H}_{2}$ and $\mathrm{CO}$ concentrations was a consequence of biological oxidation. The theoretical bacterial population sustained by trace gas scavenging $(N)$ was calculated by the methods of Conrad ${ }^{26}$ based on the observed trace gas oxidation rate $(d)$, the Gibbs free energy of gas oxidation $(\Delta G)$, and the theoretical maintenance energy of the population $\left(m_{e}\right)$. $\Delta G$ was calculated to be $-200.9 \mathrm{~kJ} \mathrm{~mol}^{-1}$ for the reaction $\mathrm{H}_{2}+0.5 \mathrm{O}_{2} \rightarrow \mathrm{H}_{2} \mathrm{O}$ and $-236.2 \mathrm{~kJ} \mathrm{~mol}^{-1}$ for the reaction $\mathrm{CO}+0.5$ $\mathrm{O}_{2} \rightarrow \mathrm{CO}_{2}$ using the Nernst equation $\left(10^{\circ} \mathrm{C}\right.$, ambient gas concentrations). $m_{e}$ was estimated to be $1.68 \mathrm{~kJ}$ per $\mathrm{C}$-mol biomass per hour using the Tijhuis equation ${ }^{55}$. Carbon fixation analysis. The soil samples were incubated with radiolabelled carbon dioxide $\left({ }^{14} \mathrm{CO}_{2}\right)$ under different conditions to determine whether their microbial communities could mediate chemosynthetic or photosynthetic $\mathrm{CO}_{2}$ fixation. Each of the soil samples $(0.25 \mathrm{~g})$ were added to sterile 4 -ml glass vials, sealed with rubber septum lids, and stored on ice before downstream analysis. Gaseous ${ }^{14} \mathrm{CO}_{2}(1 \% \mathrm{v} / \mathrm{v})$ was generated by mixing $75 \mu \mathrm{l}$ radiolabelled sodium bicarbonate solution $\left(\mathrm{NaH}^{14} \mathrm{CO}_{3}\right.$, Perkin Elmer, $\left.53.1 \mathrm{mCi} \mathrm{nmol}^{-1}\right)$ with $75 \mu \mathrm{l}$ $10 \% \mathrm{HCl}$ solution in a sealed $4-\mathrm{ml}$ glass vial and incubating for $2 \mathrm{~h}$ at room temperature. To each sample, $160 \mu \mathrm{l}$ of ${ }^{14} \mathrm{CO}_{2}(1 \% \mathrm{v} / \mathrm{v})$ gas was added using a gas-tight syringe ( $1 \mathrm{ml}$, SGE Analytical Science), obtaining initial headspace mixing ratios of 400 p.p.m.v. ${ }^{14} \mathrm{CO}_{2}$ in a headspace otherwise comprised of ambient air. In addition, $40 \mu \mathrm{l}$ standard $\mathrm{H}_{2}$ gas ( $1 \% \mathrm{v} / \mathrm{v}$, AirLiquide) was added to half of the sampling cohort to obtain simultaneous mixing ratios of 100 p.p.m.v. $\mathrm{H}_{2}$ and 400 p.p.m.v. ${ }^{14} \mathrm{CO}_{2}$. Both groups were then incubated under either light $\left(40 \mu \mathrm{mol}\right.$ photons $\mathrm{m}^{-2} \mathrm{~s}^{-1}$ under constant illumination) or dark conditions (sealed light-proof box) for $96 \mathrm{~h}$ at $10^{\circ} \mathrm{C}$. To remove any unfixed ${ }^{14} \mathrm{CO}_{2}$, incubated soils were transferred to 12 -ml scintillation vials, suspended in $2 \mathrm{ml} 10 \%$ acetic acid in ethanol, and left to dry under a heat lamp at $30^{\circ} \mathrm{C}$ for $12 \mathrm{~h}$. Ten millilitres of scintillation cocktail (EcoLume) was added and radioisotope analysis was carried out using a liquid scintillation spectrometer (Tri-Carb 2810 TR, Perkin Elmer) operating at 95\% efficiency, with background luminescence and chemiluminescence corrected through internal calibration standards. Each experiment used two Robinson Ridge soil samples in paired technical quadruplicates (performed in three separate experiments across successive weeks) and three Adams Flat samples in paired technical triplicates (performed in three separate experiments across successive weeks). Control samples were run with soils that were heat-killed for $12 \mathrm{~h}$ at $100^{\circ} \mathrm{C}$ using a cooled vacuum drying oven (Memmert $\mathrm{GmbH}$ ). Scintillation counts from heat-killed controls were subtracted and the amount of ${ }^{14} \mathrm{CO}_{2}$ fixed per sample was calculated on the basis of the reported specific radioactivity of the original bicarbonate solution. A control experiment validated that light stimulation caused a 15 -fold increase in $\mathrm{CO}_{2}$ fixation over the dark-incubated samples in a phototroph-containing soil community collected from Mitchell Peninsula in December 2005.

Data availability. The raw shotgun sequencing datasets generated during the current study have been deposited in the National Center for Biotechnology Information (NCBI) Sequence Read Archive (RR samples 1, 2 and 3 under accession numbers SRR5223441, SRR5223442 and SRR5223443, respectively). The metagenome data have been deposited into the IMG-M web portal (https://img. jgi.doe.gov/cgi-bin/m/main.cgi) under accession number 3300009400 , and the scaffolds of all $23 \mathrm{draft}$ genomes have been deposited into the IMG-M web portal under accession numbers 2667527203, 2667527204 and 2698536723-2698536743).
31. Nielsen, U. N. \& King, C. K. Abundance and diversity of soil invertebrates in the Windmill Islands region, East Antarctica. Polar Biol. 38, 1391-1400 (2015).

32. van Dorst, J. et al. Community fingerprinting in a sequencing world. FEMS Microbiol. Ecol. 89, 316-330 (2014).

33. Bolger, A. M., Lohse, M. \& Usadel, B. Trimmomatic: a flexible trimmer for Illumina sequence data. Bioinformatics 30, 2114-2120 (2014).

34. Simpson, J. T. et al. ABySS: a parallel assembler for short read sequence data. Genome Res. 19, 1117-1123 (2009).

35. Imelfort, M. et al. GroopM: an automated tool for the recovery of population genomes from related metagenomes. PeerJ 2, e603 (2014).

36. Kang, D. D., Froula, J., Egan, R. \& Wang, Z. MetaBAT, an efficient tool for accurately reconstructing single genomes from complex microbial communities. PeerJ 3, e1165 (2015).

37. Parks, D. H., Imelfort, M., Skennerton, C. T., Hugenholtz, P. \& Tyson, G. W. CheckM: assessing the quality of microbial genomes recovered from isolates, single cells, and metagenomes. Genome Res. 25, 1043-1055 (2015).

38. Bissett, A. et al. Introducing BASE: the Biomes of Australian Soil Environments soil microbial diversity database. Gigascience 5, 21 (2016).

39. Quast, C. et al. The SILVA ribosomal RNA gene database project: improved data processing and web-based tools. Nucleic Acids Res. 41, D590-D596 (2013).

40. DeSantis, T. Z. et al. Greengenes, a chimera-checked 16S rRNA gene database and workbench compatible with ARB. Appl. Environ. Microbiol. 72, 5069-5072 (2006).

41. Darling, J. A., Tsai, Y. H., Blakeslee, A. M. \& Roman, J. Are genes faster than crabs? Mitochondrial introgression exceeds larval dispersal during population expansion of the invasive crab Carcinus maenas. R. Soc. Open Sci. 1, 140202 (2014).

42. Markowitz, V. M. et al. IMG: the Integrated Microbial Genomes database and comparative analysis system. Nucleic Acids Res. 40, D115-D122 (2012).

43. Soo, R. M. et al. An expanded genomic representation of the phylum cyanobacteria. Genome Biol. Evol. 6, 1031-1045 (2014).

44. Letunic, I. \& Bork, P. Interactive Tree Of Life v2: online annotation and display of phylogenetic trees made easy. Nucleic Acids Res. 39, W475-W478 (2011).

45. Seemann, T. Prokka: rapid prokaryotic genome annotation. Bioinformatics $\mathbf{3 0}$, 2068-2069 (2014)

46. Kanehisa, M. \& Goto, S. KEGG: Kyoto encyclopedia of genes and genomes. Nucleic Acids Res. 28, 27-30 (2000).

47. Lombard, V., Golaconda Ramulu, H., Drula, E., Coutinho, P. M. \& Henrissat, B. The carbohydrate-active enzymes database (CAZy) in 2013. Nucleic Acids Res. 42, D490-D495 (2014).

48. Blin, K. et al. antiSMASH 2.0-a versatile platform for genome mining of secondary metabolite producers. Nucleic Acids Res. 41, W204-W212 (2013)

49. Park, S. W. et al. Presence of duplicate genes encoding a phylogenetically new subgroup of form I ribulose 1,5-bisphosphate carboxylase/oxygenase in Mycobacterium sp. strain JC1 DSM 3803. Res. Microbiol. 160, 159-165 (2009).

50. Tabita, F. R., Satagopan, S., Hanson, T. E., Kreel, N. E. \& Scott, S. S. Distinct form I, II, III, and IV Rubisco proteins from the three kingdoms of life provide clues about Rubisco evolution and structure/function relationships. J. Exp. Bot. 59, 1515-1524 (2008)

51. Larkin, M. A. et al. Clustal W and Clustal X version 2.0. Bioinformatics 23, 2947-2948 (2007)

52. Kumar, S., Stecher, G. \& Tamura, K. MEGA7: molecular evolutionary genetics analysis version 7.0 for bigger datasets. Mol. Biol. Evol. 33, 1870-1874 (2016).

53. Søndergaard, D., Pedersen, C. N. S. \& Greening, C. HydDB: a web tool for hydrogenase classification and analysis. Sci. Rep. 6, 34212 (2016)

54. Constant, P., Chowdhury, S. P. \& Conrad, R. Co-localization of atmospheric $\mathrm{H}_{2}$ oxidation activity and high affinity $\mathrm{H}_{2}$-oxidizing bacteria in non-axenic soil and sterile soil amended with Streptomyces sp. PCB7. Biol. Biochem. 43, 1888-1893 (2011).

55. Tijhuis, L., Van Loosdrecht, M. C. M. \& Heijnen, J. J. A thermodynamically based correlation for maintenance Gibbs energy requirements in aerobic and anaerobic chemotrophic growth. Biotechnol. Bioeng. 42, 509-519 (1993). 

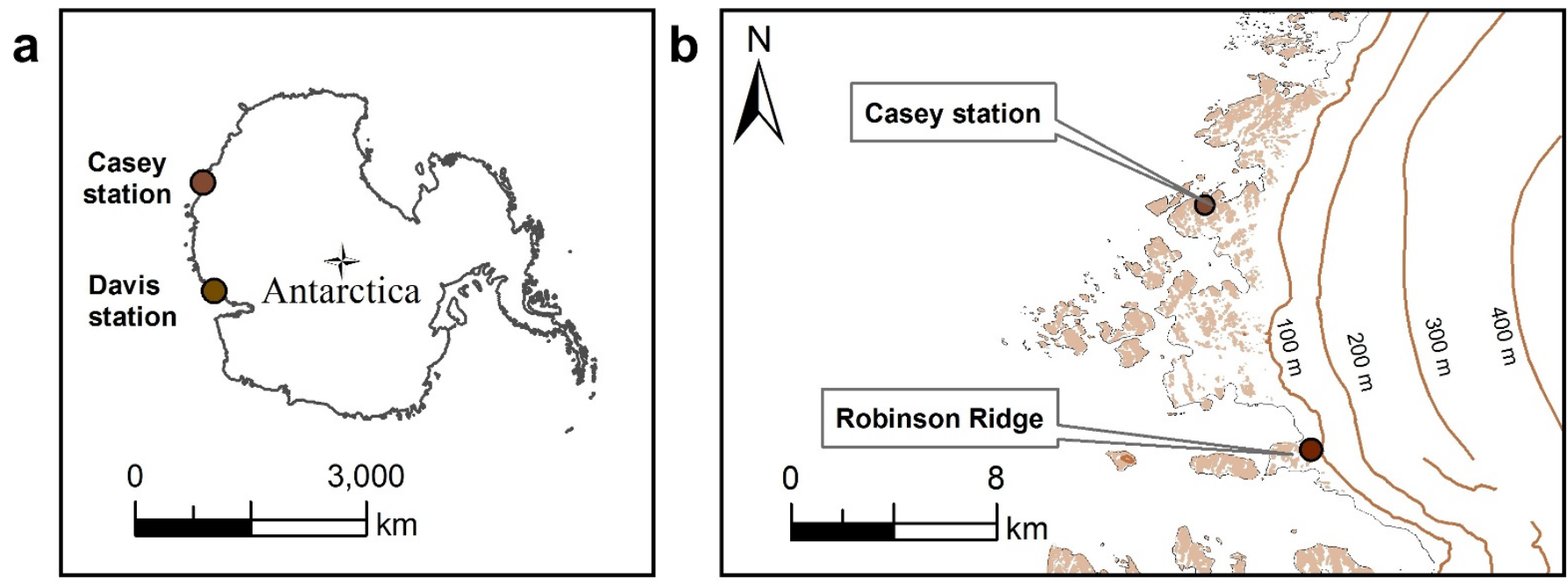

100 m contour

Coastline

Ice free area

C

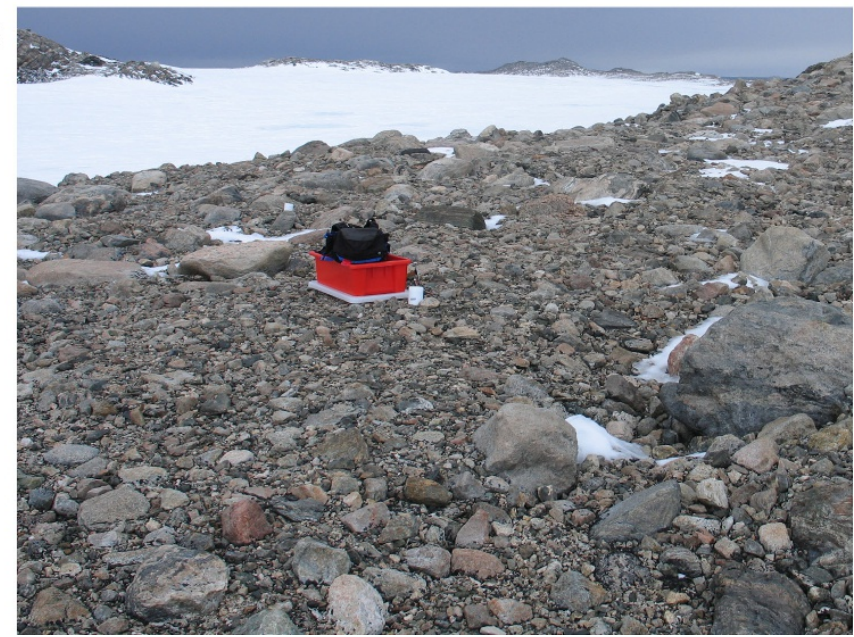

Extended Data Figure 1 | Field sites sampled in this study. a, Map

of Antarctica highlighting Casey station in the Windmill Islands and

Davis station in the Vestfold Hills, eastern Antarctica. b. The location of

Robinson Ridge with respect to Casey station. c, Photo of sampling site at d

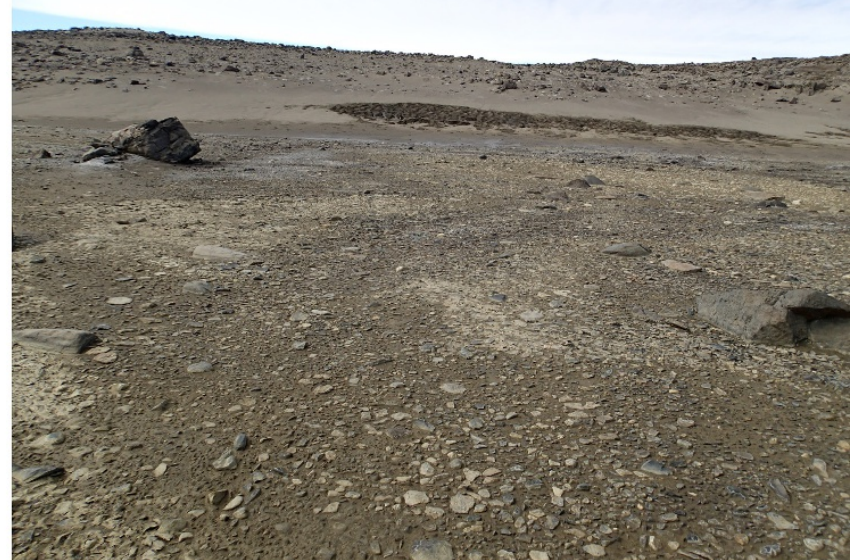

Robinson Ridge within the Windmill Islands region. d, Photo of sampling site in Adams Flat within the Vestfold Hills region. Map courtesy of D. Wilkins; Adams Flat photo courtesy of T. Mooney. 


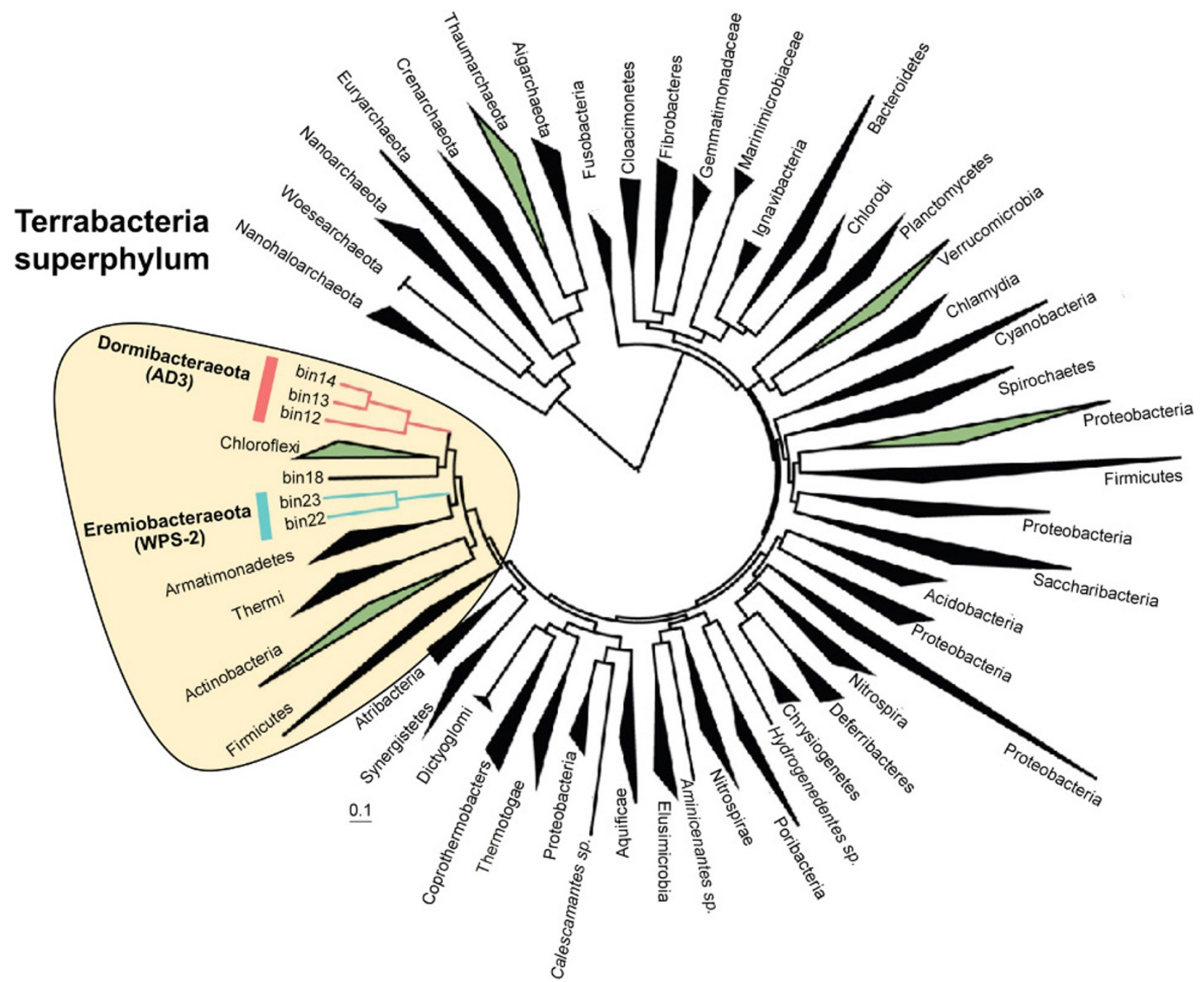

Extended Data Figure $2 \mid$ A concatenated genome tree showing phylogeny of the sequenced genomes retrieved from the Robinson Ridge metagenomes. The phyla retrieved are coloured green. The phylogeny of the three retrieved genomes of candidate phylum
Dormibacteraeota (AD3) and the two retrieved genomes of candidate phylum Eremiobacteraeota (WPS-2) is shown (coloured pink and blue, respectively). Also shown is their affiliation with the superphylum Terrabacteria (highlighted in yellow). 


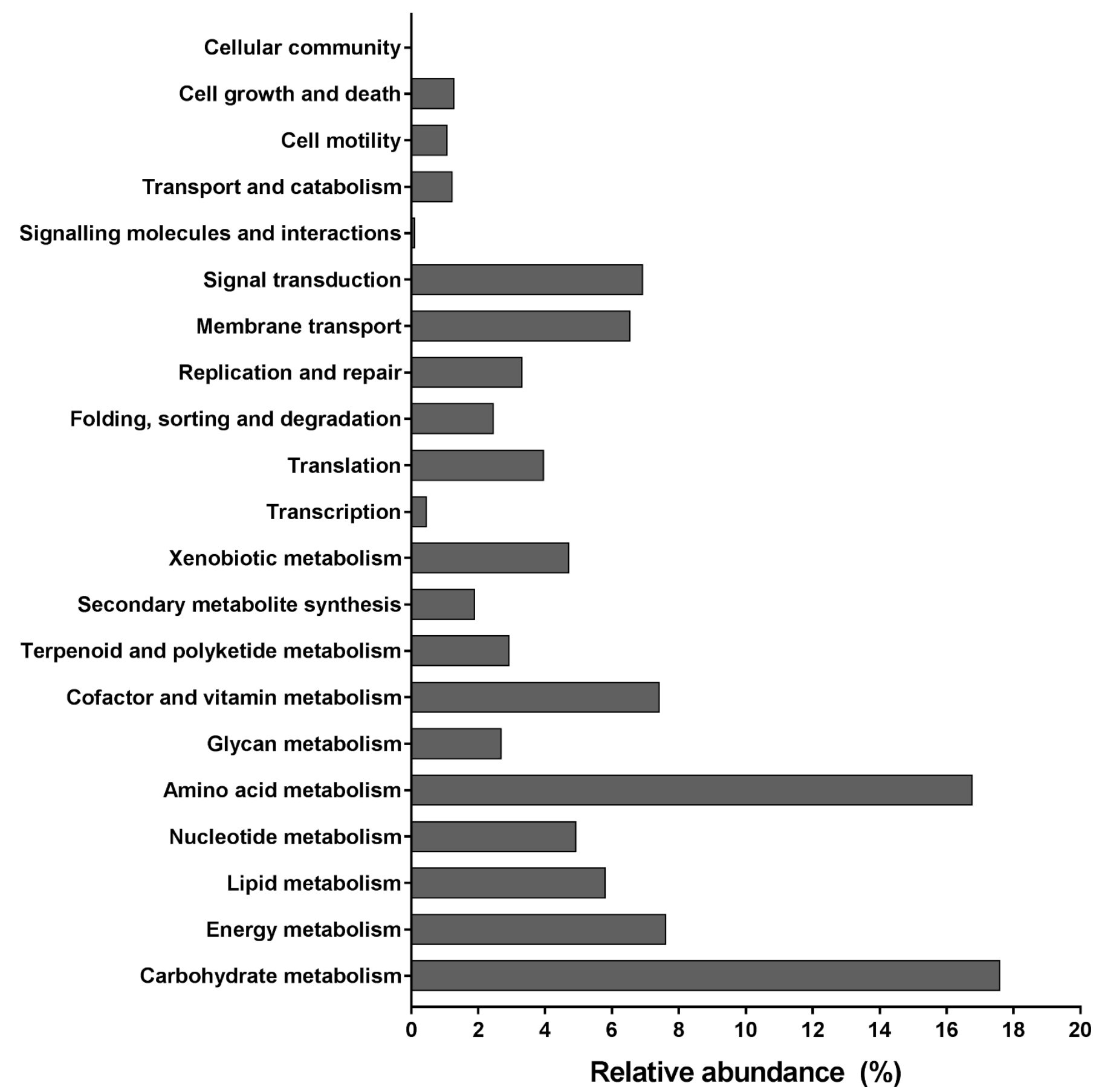

Extended Data Figure 3 | Distribution of genes in the Robinson Ridge metagenome according to the KEGG classification system. The most abundant metabolic categories identified were those associated with carbohydrate (18\%), amino acid (17\%), and energy metabolism ( $8 \%$ ). 
Bin12: Dormibacteraeota (AD3)

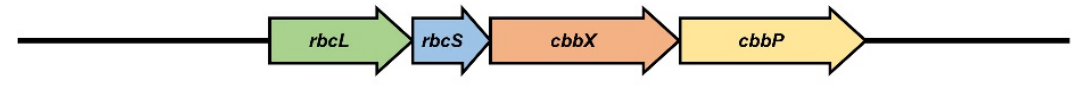

Bin22: Eremiobacteraeota (WPS-2)

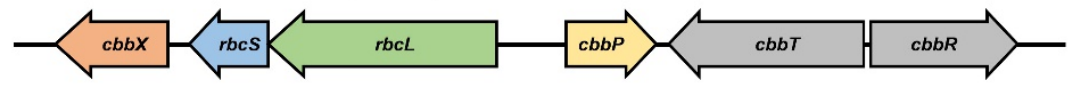

b
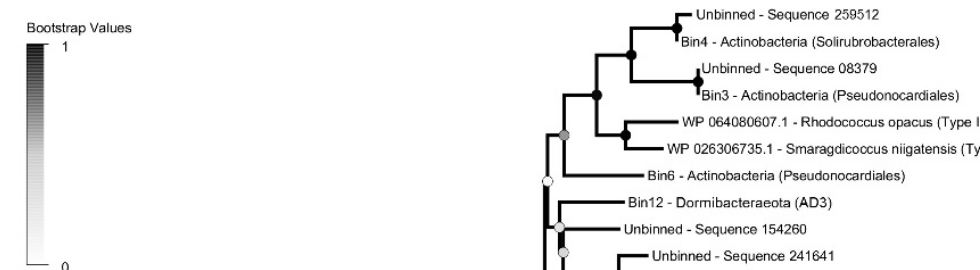

WP 064080607.1 - Rhodococcus opacus (Type IE) —WP 026306735.1 - Smaragdicoccus niigatensis (Type IE)

-

Bin12 - Dormibacteraeota (AD3)

Unbinned - Sequence 154260

Unbinned - Sequence 154260

Unbinned - Sequence 100540

$\longrightarrow$ Unbinned Sequence 00264 Unbinned - Sequence 187302

WP 044200861.1 . Oscillochloris trichoides (Type IE)

I Unbinned - Sequence 160018

WP 012852015.1 - Thermomonospora curvata (Type IE) WP 013678237.1 - Pseudonocardia dioxanivorans (Type IE) LWP 013678237.1 - Pseudonocardia dioxanivorans (Typ

- Bin7 - Actinobacteria (Pseudonocardiales)

LS Unbinned - Sequence 114617

Unbinned - Sequence 114329

Bin22 - Eremiobacteraeota (WPS-2)
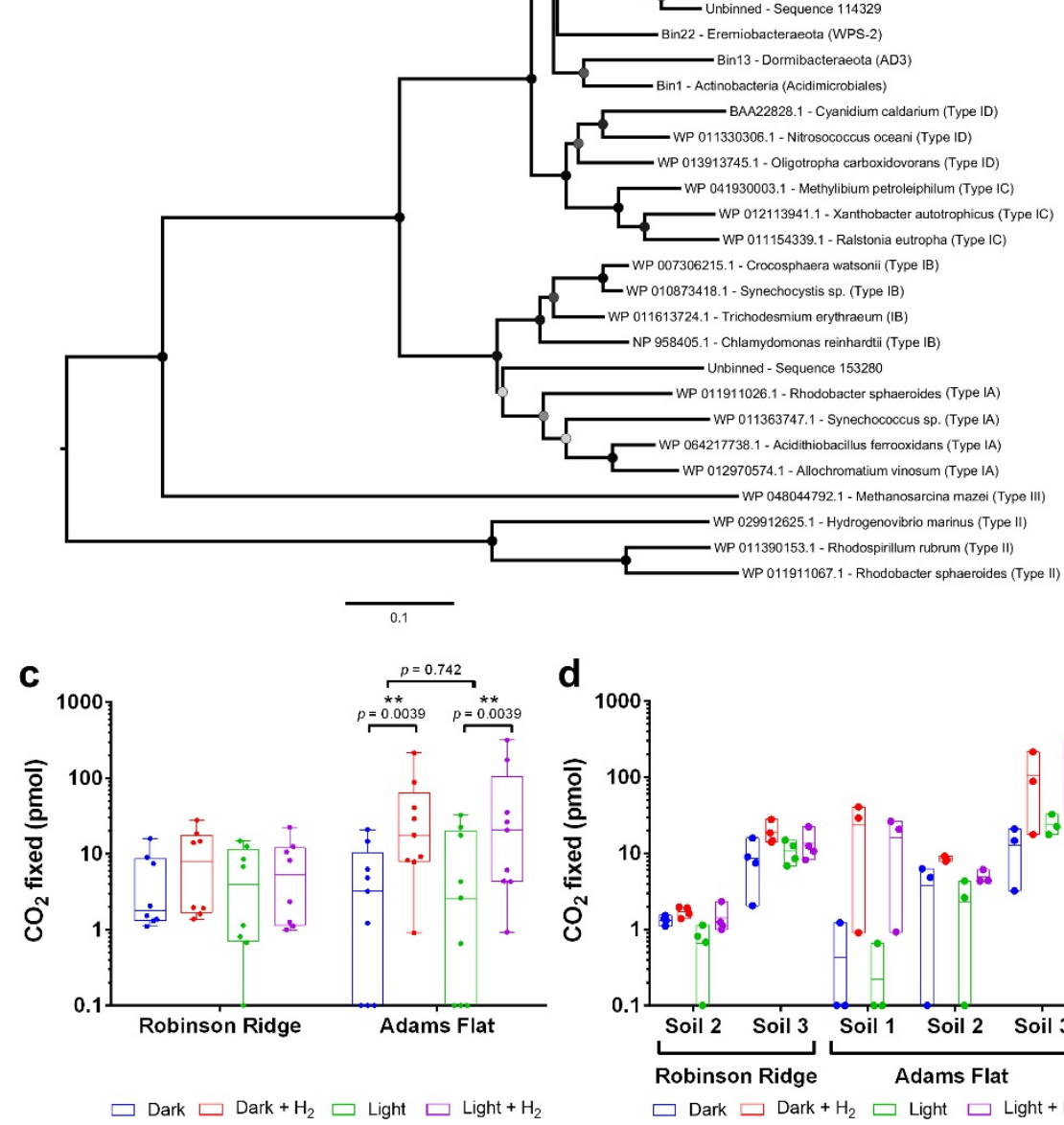

d

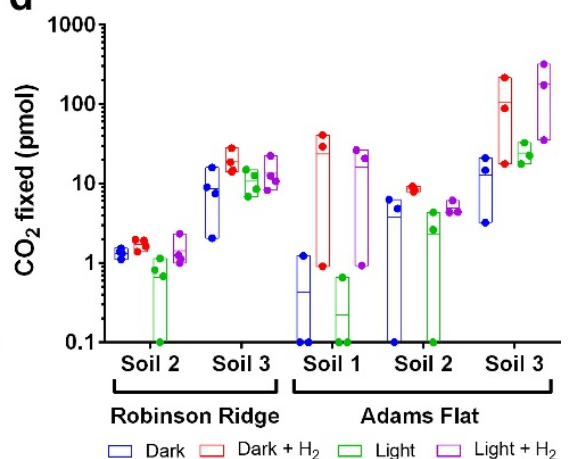

Extended Data Figure $4 \mid$ See next page for caption. 
Extended Data Figure 4 | Genetic organization, amino acid phylogeny, and inferred activity of RuBisCO enzymes in sampled soils.

a, Organization of type IE RuBisCO genes retrieved from Robinson Ridge. The genes included in Bin 12: Dormibacteraeota (AD3, top) and Bin 22: Eremiobacteraeota (WPS-2, bottom) are shown. $r b c S$, RuBisCO small subunit; $r b c L$, RuBisCO large subunit; $c b b X$, RuBisCO expression protein; $c b b P$, phosphoribulokinase; $c b b R$, transcriptional regulator protein; $c b b T$, transketolase. b, Expanded phylogenetic tree of RuBisCO large subunit genes retrieved from Robinson Ridge metagenomes. The phylogenetic tree was generated by the maximum-likelihood method and robustness was tested with 500 replicates. The majority of sequences within the metagenome and bins encode type IE RuBisCO (chemosynthesis-

type), except for one of the unbinned sequences, which encodes a type IA RuBisCO (photosynthesis-type). c, Box plots showing amount of

${ }^{14} \mathrm{C}$-labelled $\mathrm{CO}_{2}$ assimilated by Robinson Ridge and Adams Flat soil communities following light or $\mathrm{H}_{2}$ stimulation. Results are shown for two biologically independent Robinson Ridge soils (technical quadruplicate) and three biologically independent Adams Flat soils (technical triplicate). Centre values show medians. Maxima, upper and lower quartile, and minima values are also shown. Where sample size is appropriate, statistical significance between paired technical replicates was tested using a two-tailed Wilcoxon signed-rank test. d, Amount of ${ }^{14} \mathrm{C}$-labelled $\mathrm{CO}_{2}$ assimilated for each individual Robinson Ridge and Adams Flat soil tested. Soils are named as in Supplementary Table 1 and results are shown for technical quadruplicates (Robinson Ridge) and technical triplicates (Adams Flat). Centre values show means, upper values show maxima, and lower values show minima. Although a variable level of basal $\mathrm{CO}_{2}$ fixation was observed, these results show that $\mathrm{H}_{2}$ addition consistently stimulated $\mathrm{CO}_{2}$ fixation. 

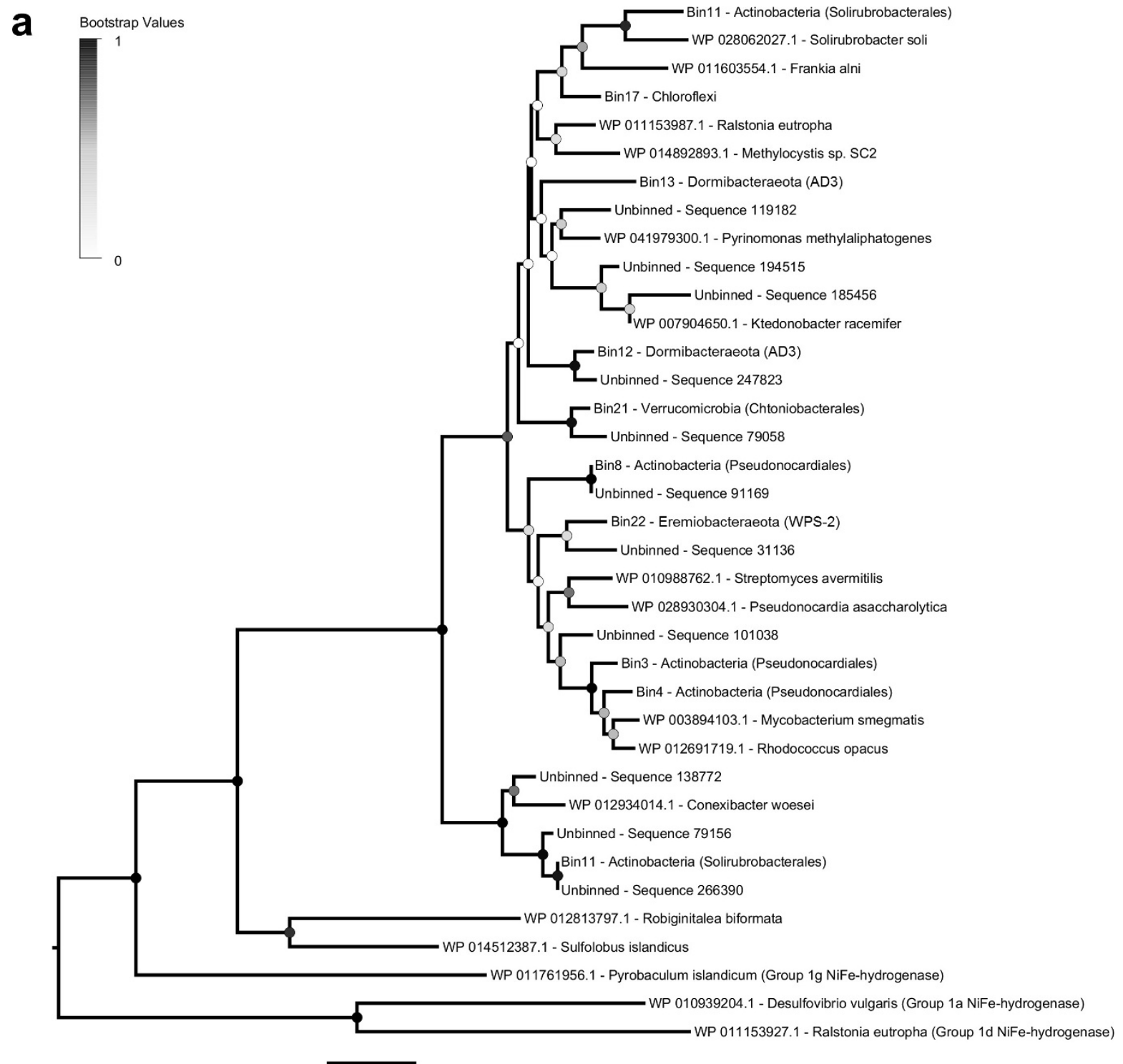

0.2

b

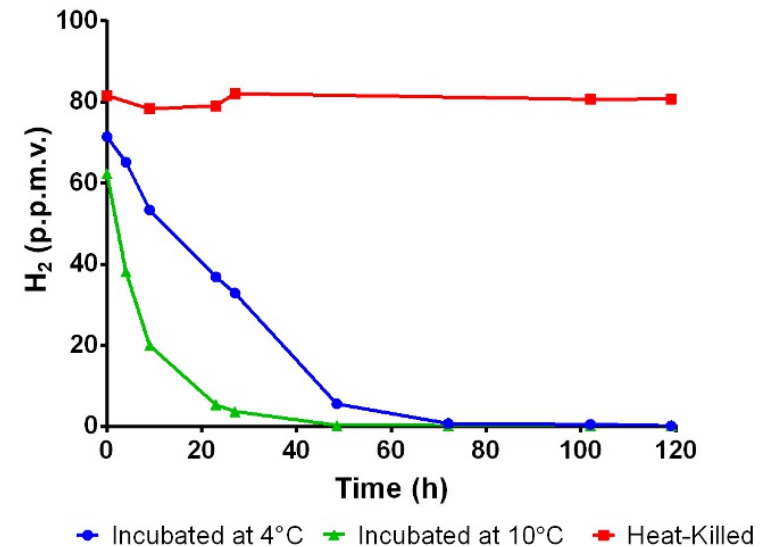

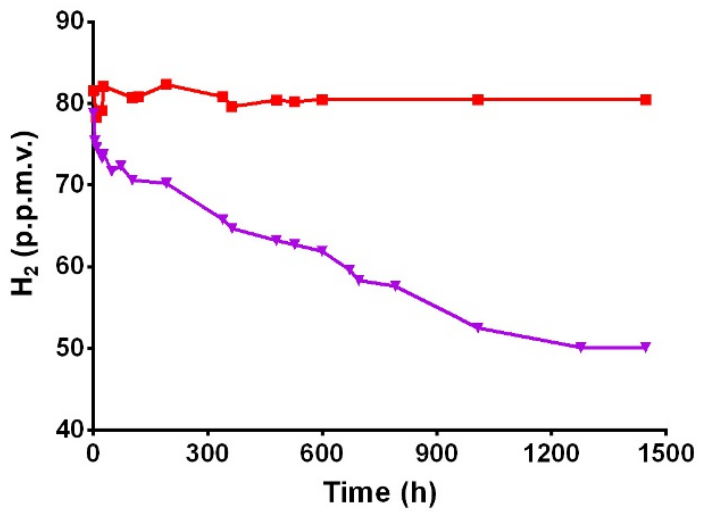

* Incubated at $-12^{\circ} \mathrm{C} \quad-$ Heat-Killed
Extended Data Figure 5 | Amino acid phylogeny and inferred activity of hydrogenase enzymes in sampled soils. a, Expanded phylogenetic tree of $[\mathrm{NiFe}]$-hydrogenase large subunit genes retrieved from the Robinson Ridge metagenome data. The phylogenetic tree was generated by the maximum-likelihood method and robustness was tested with 500 replicates. Hydrogenase genes were common within the metagenome and bins. They clustered exclusively with the group $1 \mathrm{~h}$ [NiFe]-hydrogenases, suggesting that they mediate atmospheric $\mathrm{H}_{2}$ scavenging. $\mathbf{b}, \mathrm{H}_{2}$ oxidation activities of Robinson Ridge soils incubated at $10^{\circ} \mathrm{C}, 4^{\circ} \mathrm{C}$, and $-12^{\circ} \mathrm{C}$. Gas chromatography traces show $\mathrm{H}_{2}$ oxidation of soils in modified ambient air headspaces. Results are shown from one soil sample (Soil 1) following averaging of results from technical triplicates. 


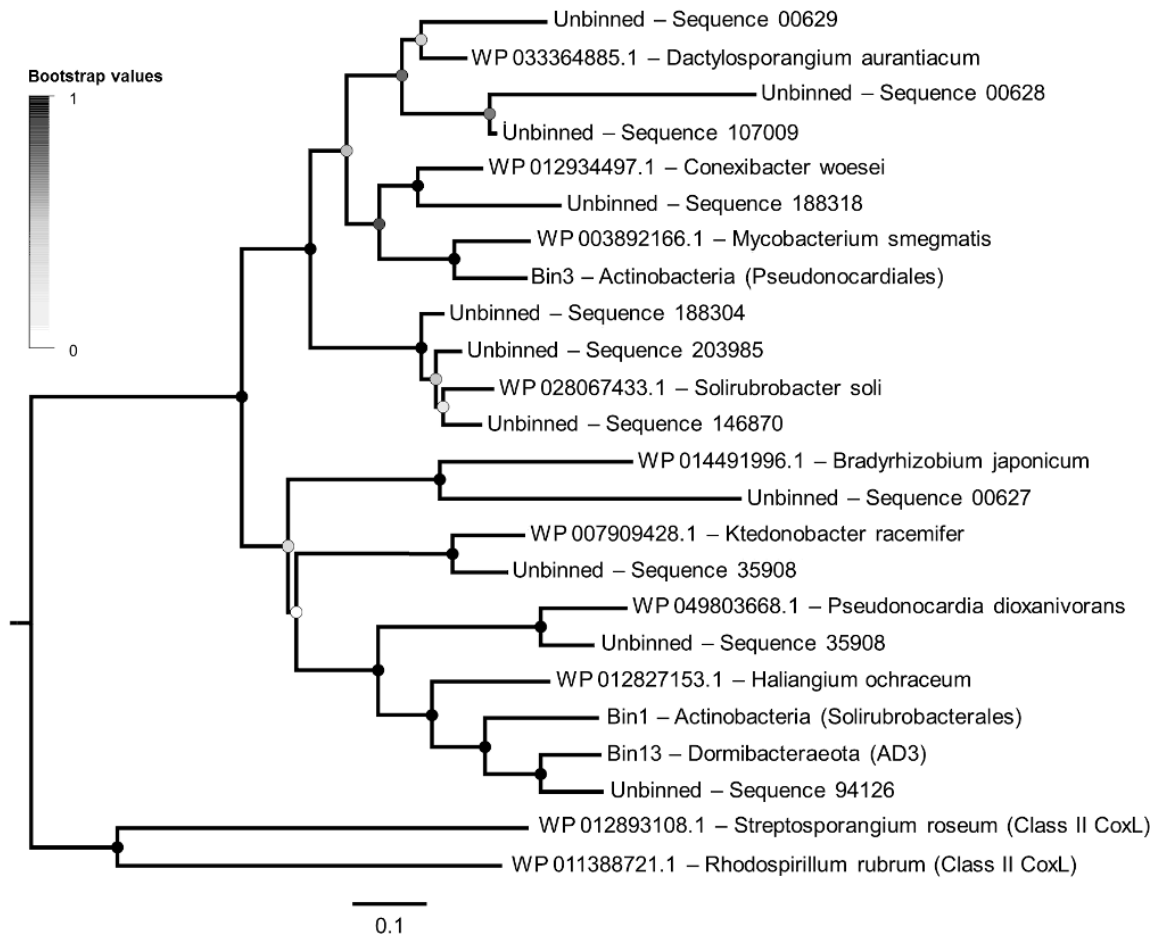

b

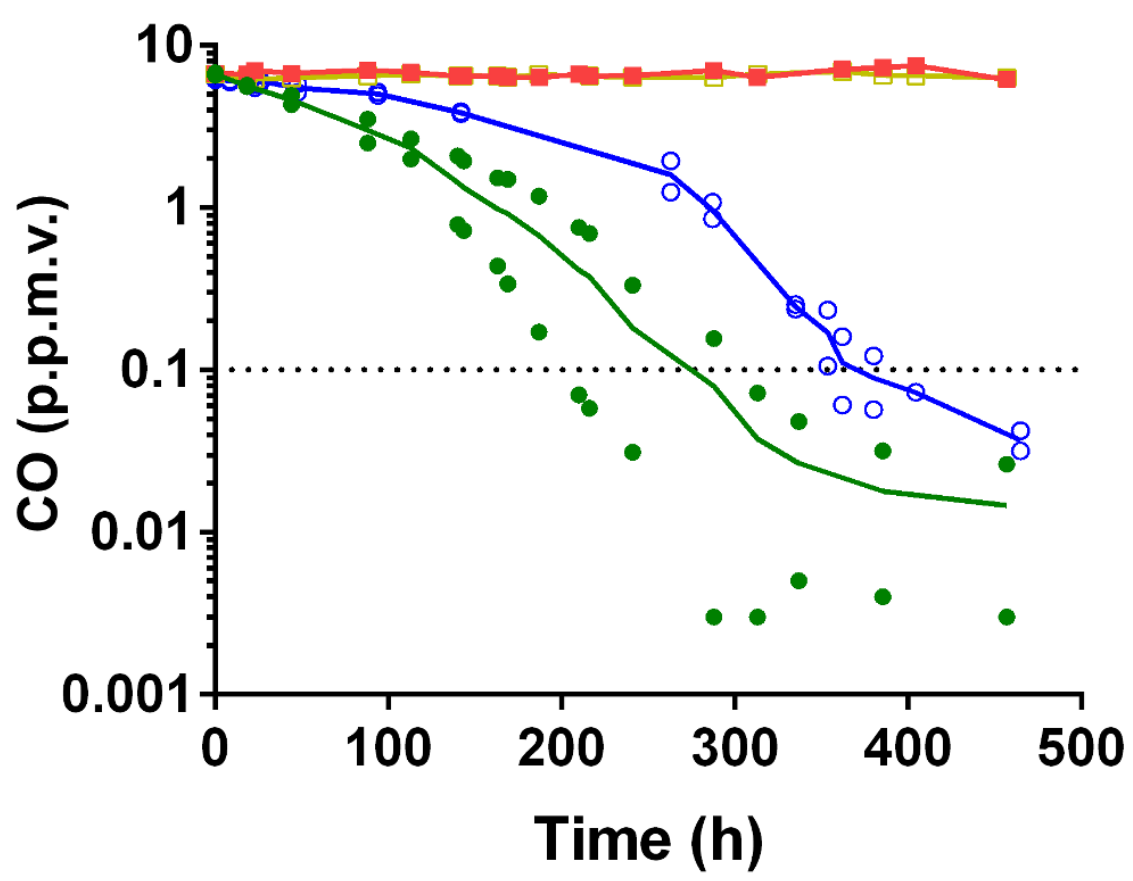

$\rightarrow$ Robinson Ridge

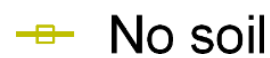

Extended Data Figure 6 | Amino acid phylogeny and inferred activity of carbon monoxide dehydrogenase enzymes in sampled soils.

a, Phylogenetic tree of type I [MoCu]-hydrogenase large subunit genes retrieved from the Robinson Ridge metagenome data. The phylogenetic tree was generated by the maximum-likelihood method and robustness was tested with 500 replicates. Multiple Actinobacteria and AD3 genomes

\section{- Adams Flat $\rightarrow$ Heat-killed}

encoded this subunit, suggesting that they may mediate atmospheric $\mathrm{CO}$ scavenging. $\mathbf{b}$, Gas chromatography results showing oxidation of atmospheric $\mathrm{CO}$ (mixing ratio 0.10 p.p.m.v.) mediated by the soil communities at $10^{\circ} \mathrm{C}$ in modified ambient air headspaces. For both the Robinson Ridge and Adams Flat datasets, values are shown for two biologically independent soils following averaging of technical duplicates. 


\section{hhyL \\ Robinson Ridge}

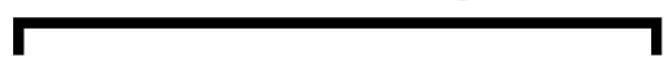

\section{rbcL1E \\ Robinson Ridge}

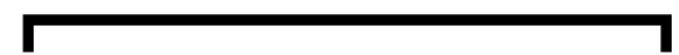

$\begin{array}{llll}5 & 6 & 7 & 8\end{array}$

\section{hhyL \\ Adams Flat}

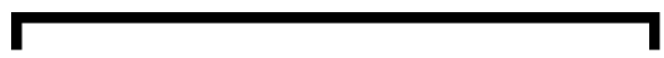

M

12

23

34

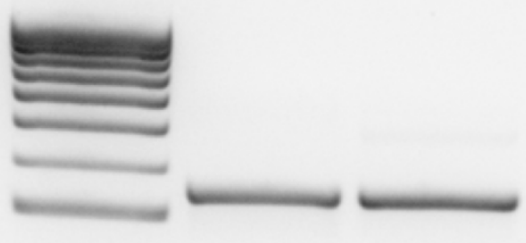

Extended Data Figure 7 | Presence and expression of trace gas scavenging genes in Robinson Ridge and Adams Flat soil samples. The presence and expression of the genes encoding the group $1 \mathrm{~h}[\mathrm{NiFe}]-$ hydrogenase large subunit $(h h y L)$ and type IE RuBisCO large subunit $(r b c L 1 E)$ was confirmed by agarose gel electrophoresis. Lane M shows the DNA ladder (Bioline 100-bp Molecular Weight Marker). Lanes 1 and 5 show amplifications from community DNA extracted from the soil samples. Lanes 2 and 6 show amplifications of cDNA derived from reverse transcription of community RNA extracted from the soil samples.

\section{rbcL1E \\ Adams Flat}
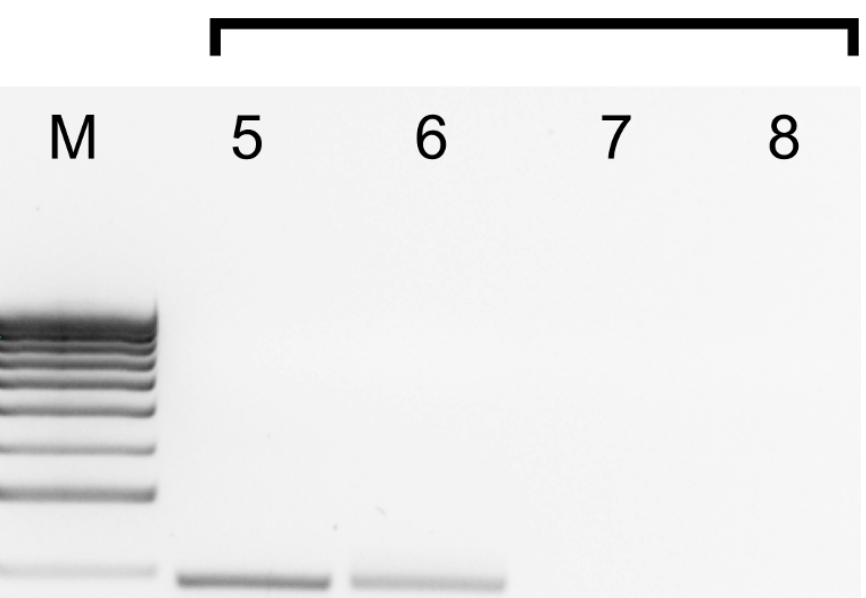

No template negative controls for both the PCR (lanes 3, 7) and RT-PCR (lanes 4,8 ) are also shown. Independent PCR and RT-PCR reactions were conducted twice for both Robinson Ridge and Adams Flat soil samples, with similar results. For gel source data, see Supplementary Fig. 1. For carbon monoxide dehydrogenase, the bands obtained from agarose gel electrophoresis were blurred owing to the degeneracy of the primer set. Sequencing of the bands confirmed the expression of carbon monoxide dehydrogenase genes homologous to GenBank accession numbers EU888210 (79\%), EU888266 (79\%), and KJ468250 (88\%). 


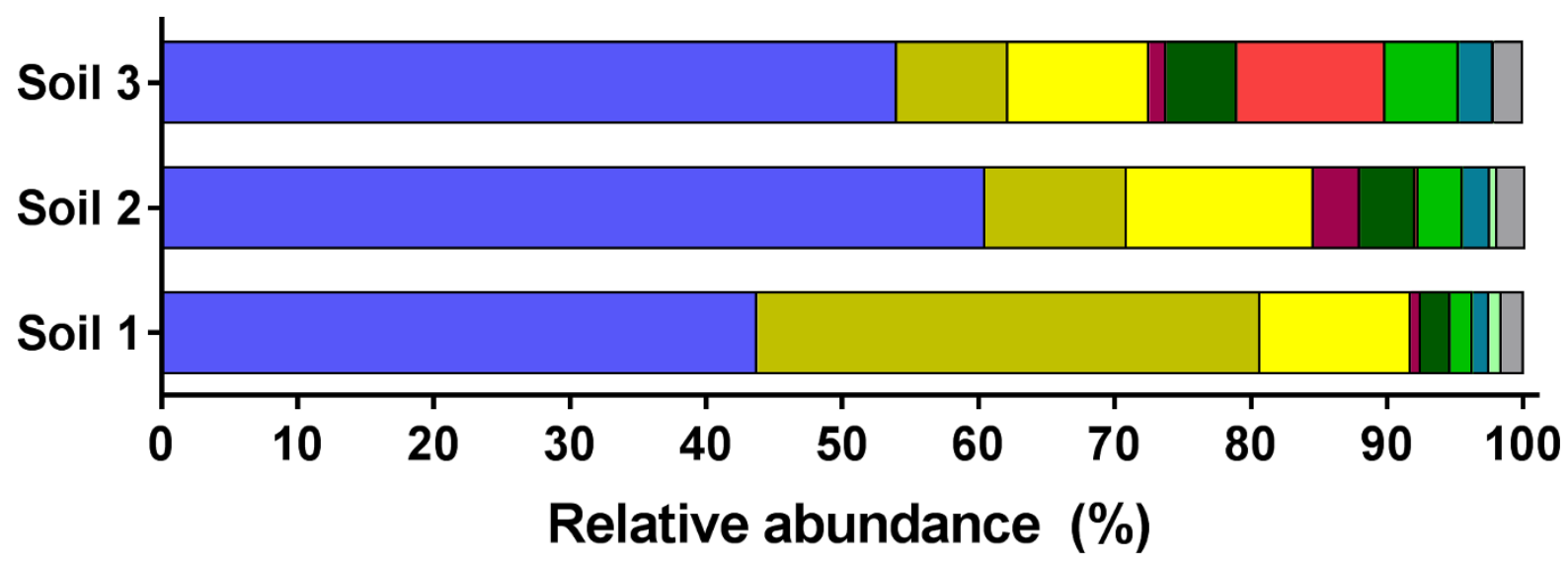

$\square$ Gemmatimonadetes

$\square$ Thermi

\section{Proteobacteria}

\section{Bacteroidetes}

\section{Actinobacteria}

Extended Data Figure $8 \mid$ Microbial community structure of Adams

Flat soil samples. Community structure was determined by targeted

amplicon sequencing of bacterial 16S rRNA genes from three biologically $\square$ Other Bacteria

$\square$ Cyanobacteria

$\square$ Planctomycetes

$\square$ Chloroflexi

$\square$ Acidobacteria

independent soil samples. All samples show a high abundance of potential trace gas scavengers from the phylum Actinobacteria and a low abundance of phototrophs from the phylum Cyanobacteria. 


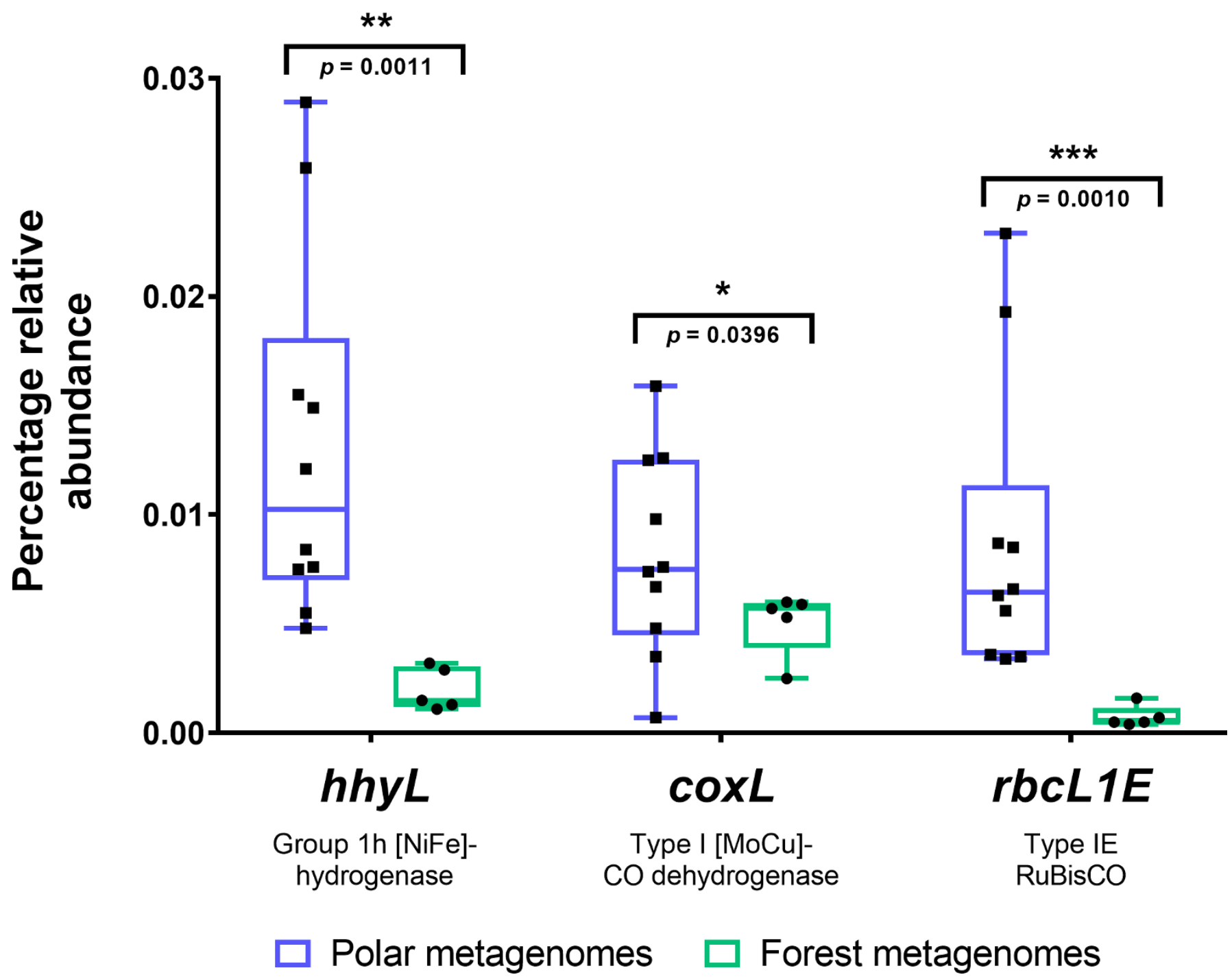

Extended Data Figure 9 | Comparison of the relative abundance of genes associated with trace gas scavenging in public metagenomes. The relative abundance of the genes $h h y L$, coxL, and $r b c L 1 E$ was compared between McMurdo Dry Valley and forest metagenomes publicly available through JGI. Results are shown for ten biologically independent McMurdo
Dry Valley metagenomes and five biologically independent forest metagenomes. Centre values show medians; boxes show upper and lower quartiles; whiskers show maxima and minima. Statistical significance was tested using a one-tailed Student's $t$-test. 


\section{nature research}

Corresponding author(s): Ferrari

\section{Life Sciences Reporting Summary}

Nature Research wishes to improve the reproducibility of the work that we publish. This form is intended for publication with all accepted life science papers and provides structure for consistency and transparency in reporting. Every life science submission will use this form; some list items might not apply to an individual manuscript, but all fields must be completed for clarity.

For further information on the points included in this form, see Reporting Life Sciences Research. For further information on Nature Research policies, including our data availability policy, see Authors \& Referees and the Editorial Policy Checklist.

\section{- Experimental design}

\section{Sample size}

Describe how sample size was determined.

2. Data exclusions

Describe any data exclusions.

\section{Replication}

Describe whether the experimental findings were reliably reproduced.

\section{Randomization}

Describe how samples/organisms/participants were allocated into experimental groups.

5. Blinding

Describe whether the investigators were blinded to group allocation during data collection and/or analysis.
No statistical methods were used to predetermine sample sizes. Three biologically independent soil samples were collected from the two sampling sites, Robinson Ridge (December 2005) and Adams Flat (January 2014). For both sites, samples were collected along a spatially explicit sampling design comprised of three $300 \mathrm{~m}$ long transects separated by two meter distances from each other. This sample size was sufficient to perform the in-depth metagenome analyses and supporting biochemical assays needed to confirm that novel primary production processes operating in these soils. However, the relatively limited sample size meant that we were unable to confirm whether trace gas scavenging is a widespread mechanism operating in Antarctic soils. Due to the very limited amounts of Robinson Ridge soils that remained following metagenome and physicochemical analysis, we used sample sizes lower than three for some gas chromatography and carbon fixation experiments.

No exclusions.

All attempts at replication were successful. For carbon fixation studies (Figure 3b, Extended Data Figure 4), we observed that there was a large and unexplained variation in basal levels of $\mathrm{CO} 2$ that was fixed between each of the five soils tested. However, the core finding that $\mathrm{H} 2$ addition stimulated carbon fixation was reliably reproduced. $\mathrm{H} 2$ addition stimulated all 17 sample pairs in the dark condition and 15 of the 17 sample pairs under light illumination.

Samples were not randomized for the experiments.

Blinding was not applicable to use in this study as we were investigating a new process and only two sites were examined. 


\section{Statistical parameters}

For all figures and tables that use statistical methods, confirm that the following items are present in relevant figure legends (or in the Methods section if additional space is needed).

$\mathrm{n} / \mathrm{a}$ Confirmed

The exact sample size ( $n$ ) for each experimental group/condition, given as a discrete number and unit of measurement (animals, litters, cultures, etc.)

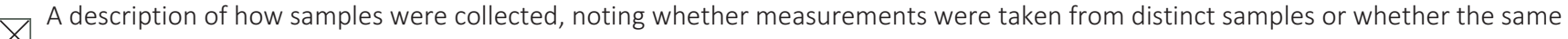
sample was measured repeatedly

$\bigotimes$ A statement indicating how many times each experiment was replicated

The statistical test(s) used and whether they are one- or two-sided (note: only common tests should be described solely by name; more complex techniques should be described in the Methods section)

$\bigotimes$ A description of any assumptions or corrections, such as an adjustment for multiple comparisons

$\bigotimes$ The test results (e.g. $P$ values) given as exact values whenever possible and with confidence intervals noted

Х A clear description of statistics including central tendency (e.g. median, mean) and variation (e.g. standard deviation, interquartile range)

Clearly defined error bars

See the web collection on statistics for biologists for further resources and guidance.

\section{- Software}

Policy information about availability of computer code

\section{Software}

Describe the software used to analyze the data in this study.

ARC GIS 10.1, Trimmomatic 0,36, CLC Genomics Workbench v8, BamM 1.4.1, GroopM 0.3, MetaBAT 0.25.2, CheckM v0.9.4, RefineM 0.0.20, CommunityM 1.0.6, FastTree 2.1, iTOL v3.6, dbCAN 5.0, ClustalX 2.0, MEGA7, Antismash 2.0, Graphpad Prism 7, BBMap 35.66, Prokka 1.12.

For manuscripts utilizing custom algorithms or software that are central to the paper but not yet described in the published literature, software must be made available to editors and reviewers upon request. We strongly encourage code deposition in a community repository (e.g. GitHub). Nature Methods guidance for providing algorithms and software for publication provides further information on this topic.

\section{- Materials and reagents}

Policy information about availability of materials

\section{Materials availability}

Indicate whether there are restrictions on availability of unique materials or if these materials are only available for distribution by a for-profit company.

\section{Antibodies}

Describe the antibodies used and how they were validated for use in the system under study (i.e. assay and species).

10. Eukaryotic cell lines

a. State the source of each eukaryotic cell line used.

b. Describe the method of cell line authentication used.

c. Report whether the cell lines were tested for mycoplasma contamination.

d. If any of the cell lines used are listed in the database of commonly misidentified cell lines maintained by ICLAC, provide a scientific rationale for their use.
All materials are available. However, only limited quantities remain of the Antarctic soil samples used for this study.

Not applicable.

Not applicable.

Not applicable.

Not applicable.

Not applicable. 
Policy information about studies involving animals; when reporting animal research, follow the ARRIVE guidelines

11. Description of research animals

Provide details on animals and/or animal-derived Not applicable. materials used in the study.

Policy information about studies involving human research participants

12. Description of human research participants

Describe the covariate-relevant population

Not applicable.

characteristics of the human research participants. 